\title{
Glycation modulates glutamatergic signalling and exacerbates Parkinson's disease-like phenotypes
}

\author{
Ana Chegão ${ }^{1}$, Mariana Guarda ${ }^{1}$, Bruno M. Alexandre ${ }^{2,3}$, Liana Shvachiy ${ }^{4}$, Mariana \\ Temido-Ferreira ${ }^{5}$, Inês Marques-Morgado ${ }^{5}$, Bárbara Fernandes Gomes ${ }^{1}$, Rune \\ Matthiesen ${ }^{1}$, Luísa V. Lopes ${ }^{5}$, Pedro R. Florindo ${ }^{6}$, Ricardo Anjos-Gomes ${ }^{2,3}$, Patrícia \\ Gomes-Alves $^{2,3}$, Joana E. Coelho ${ }^{5}$, Tiago Fleming Outeiro ${ }^{4,7,8,9^{*}}$, Hugo Vicente Miranda ${ }^{{ }^{*}}$
}

Alpha-synuclein (aSyn) is assumed to be a central player in the pathogenesis of synucleinopathies due to its accumulation in typical protein aggregates in the brain. However, it is still unclear how it contributes to neurodegeneration. Type-2 diabetes mellitus is a risk factor for Parkinson's disease and, one common molecular alteration among these disorders is an age-associated increase in protein glycation. Thus, we hypothesized that glycation-induced dysfunction of neuronal pathways might be an underlying molecular cause of synucleinopathies. Here, we evaluated if increased brain glycation modulated motor and/or non-motor phenotypes in a mouse model of synucleinopathies. In addition, we dissected the specific impact of methylglyoxal (MGO, a glycating agent) in mice overexpressing aSyn in the brain, and unveiled the major molecular pathways altered. Age-matched (16 weeks old) male aSyn transgenic (Thy1-aSyn) or WT mice received a single dose of MGO or vehicle via intracerebroventricular (ICV) injection. Behavioural phenotypes were analysed 4 weeks post-treatment, and, at the end of the tests, biochemical and histological studies were conducted on brain tissue. We found that glycation potentiates motor dysfunction, assessed by vertical pole, rotarod and hindlimb clasping tests in Thy1-aSyn mice. In addition, it induces cognitive impairment ( $Y$ maze test), olfactory disturbances (block test), and colonic dysfunction. These behavioural changes were accompanied by the accumulation of aSyn in the midbrain, striatum, and prefrontal cortex, and by an overall increase in glycation in the midbrain and cerebellum. Furthermore, MGO induced neuronal and dopaminergic cell loss in the midbrain of Thy1-aSyn mice. Quantitative proteomic analysis revealed that, in Thy1-aSyn mice, MGO mainly impacts on glutamatergic proteins in the midbrain, but not in the prefrontal cortex, where it mainly affects the electron transport chain. Among the altered proteins in the midbrain, we found an upregulation of N-Methyl-DAspartate (NMDA) and $\alpha$-amino-3-hydroxy-5-methyl-4-isoxazolepropionic acid (AMPA) glutamate receptors levels, glutaminase, vesicle glutamate transporter (VGLUT), and the excitatory amino acid transporter (EAAT1), suggesting potentiation of glutamatergic signalling. Overall, we demonstrated that MGO-induced glycation accelerates Parkinsonian-like sensorimotor and cognitive alterations. The increase in glutamatergic-related proteins in the midbrain may represent a compensatory mechanism to the MGO-induced dopaminergic neurodegeneration. Our study sheds light into the enhanced vulnerability of the midbrain in Parkinson's disease-related synaptic dysfunction that, ultimately leads to cell loss, and provides molecular insight into the observation that glycation suppressors and anti-glutamatergic drugs hold promise as disease-modifying therapies for synucleinopathies.

${ }^{1}$ CEDOC, NOVA Medical School, NMS, Universidade NOVA de Lisboa, 1169-056, Lisboa, Portugal

${ }^{2}$ Instituto de Tecnologia Química e Biológica António Xavier, Universidade Nova de Lisboa, Av. Da República, $2780-157$ Oeiras, Portugal

${ }_{3}$ iBET, Instituto de Biologia Experimental e Tecnológica, Apartado 12, 2781-901 Oeiras, Portugal

${ }^{4}$ Department of Experimental Neurodegeneration, Center for Biostructural Imaging of Neurodegeneration, University Medical Center Göttingen, Germany

${ }^{5}$ Instituto de Medicina Molecular João Lobo Antunes, Faculdade de Medicina da Universidade de Lisboa, Portugal

${ }^{6}$ Instituto de Investigação do Medicamento (iMed.ULisboa), Faculdade de Farmácia, Universidade de Lisboa, 1649-003 Lisboa, Portugal 
bioRxiv preprint doi: https://doi.org/10.1101/2021.08.24.457507; this version posted August 25, 2021. The copyright holder for this preprint (which was not certified by peer review) is the author/funder, who has granted bioRxiv a license to display the preprint in perpetuity. It is made available under aCC-BY-NC-ND 4.0 International license.

${ }^{7}$ Max Planck Institute for Experimental Medicine, 37075 Göttingen, Germany.

8 Translational and Clinical Research Institute, Faculty of Medical Sciences, Newcastle University, NE2 4HH, United Kingdom.

${ }^{9}$ Scientific employee with an honorary contract at German Center for Neurodegenerative Diseases (DZNE), 37075 Göttingen, Germany.

*Correspondence to: Hugo Vicente Miranda

DysBrainD: Dysmetabolism in Brain Diseases Lab, CEDOC, NOVA Medical School, Universidade NOVA de Lisboa, Rua Câmara Pestana, № 6, Edifício CEDOC II, Office 2.27, 1150-082 Lisboa, Portugal

E-mail: hmvmiranda@nms.unl.pt

\author{
*Correspondence may also be addressed to: Tiago Fleming Outeiro \\ Department of Experimental Neurodegeneration, \\ University Medical Center Gottingen, Waldweg 33, 37073 Gottingen, Germany \\ E-mail: touteir@gwdg.de
}

Keywords: Parkinson's disease, alpha-synuclein; glycation; neurodegeneration; glutamatergic system

Abbreviations: aSyn = Alpha-synuclein; AGEs = advanced glycation end products; $\mathrm{AMPA}=\alpha$-amino-3-hydroxy-5methyl-4-isoxazolepropionic acid; $B G=$ basal ganglia; $C E L=N($ epsilon)-(carboxyethyl)lysine; EAAT1 = excitatory amino acid transporter; $\mathrm{GO}=$ Gene Ontology; ICV = intracerebroventricular; KEGG = Kyoto Encyclopaedia of Genes and Genomes; $L B=$ Lewy bodies; $L N=$ Lewy neurites; $M G O=$ methylglyoxal; NMDA = N-Methyl-D-Aspartate (NMDA); PTMs = posttranslational modifications; SNpc = substantia nigra pars compacta; SWATH-MS = sequential window acquisition of all theoretical mass spectra; $\mathrm{TH}=$ tyrosine hydroxylase; $\mathrm{VGLUT}=$ vesicle glutamate transporter.

\section{Introduction}

Aging is an inevitable process that increases the risk for a number of conditions, including neurodegenerative disorders, such as Parkinson's disease. Neurodegenerative disorders are typically associated with the misfolding and aggregation of specific proteins in the brain and other tissues. However, the molecular mechanisms that trigger these phenomena are still elusive.

Parkinson's disease is one of several disorders known as synucleinopathies due to the misfolding and aggregation of alpha-synuclein $(\mathrm{aSyn})^{1,2}$, a protein abundant in the brain that is also present in other tissues. Synucleinopathies include dementia with Lewy bodies, multiple system atrophy, and pure autonomic failure ${ }^{3-5}$. Parkinsonism is a clinical syndrome characterized by resting tremor, bradykinesia, muscular rigidity, postural instability, and gait impairment $^{6-8}$. Nevertheless, the clinical spectrum of Parkinson's disease includes several non-motor features such as cognitive impairment, hyposmia, obstipation, anxiety and depression, sleep disturbances, pain, and fatigue ${ }^{7,9-11}$.

aSyn is a natively unfolded protein that, under certain conditions, is prone to aggregation ${ }^{2,12-15}$. Several factors contribute to the oligomerization and fibrillization of aSyn, including high protein concentration, molecular crowding, mutations, posttranslational modifications (PTMs), and interactions with specific metals and small molecules ${ }^{16,17}$.

Physiologically, Parkinson's disease is characterized by pronounced synaptic alterations and dysregulation of multiple neurotransmission pathways. Pathologically, Parkinson's disease is characterized by the loss of dopaminergic neurons in the substantia nigra pars compacta (SNpc) and by the presence of proteinaceous aggregates primarily composed of aSyn, known as Lewy bodies and Lewy neurites, in surviving neurons ${ }^{1,18-21}$. The pathological oligomerization and aggregation of aSyn is suggested to, somehow, trigger the degeneration of dopaminergic neurons in the $\mathrm{SNpc}^{20-22}$ and, the consequent depletion of dopamine in the striatum induces alterations in dopamine signalling ${ }^{23-26}$ and major functional alterations in glutamatergic synapses ${ }^{27-32}$. Glutamate is the predominant excitatory neurotransmitter in the basal ganglia $(B G)^{33}$. Although the striatum contains the highest density of glutamate receptors in the BG, glutamate or glutamate-dopamine neurons are intermixed with midbrain dopaminergic neurons. Interestingly, the SNpc is rich in NMDA and AMPA glutamate receptors, as well as in metabotropic glutamate receptors ${ }^{34-36}$. It is believed that the increase in firing of subthalamic nucleus neurons in 
Parkinson's disease acts as a compensatory mechanism to increase the release of dopamine from the surviving dopaminergic neurons in the SNpc in order to maintain dopamine homeostasis ${ }^{37}$. Furthermore, dopaminergic denervation also induces dysfunctional cortico-striatal glutamate release ${ }^{38}$, thereby eliciting an excitotoxic cascade that promotes further dopaminergic neuronal loss and neurodegeneration ${ }^{39-41}$.

Since genetic alterations account for a smaller fraction of Parkinson's disease cases, it is imperative to identify and better understand the role of risk factors in the pathogenesis of this disorder. Type-2 diabetes mellitus, a widespread chronic metabolic disease, has been established as an important risk factor for Parkinson's disease and other neurodegenerative diseases ${ }^{42,43}$. Epidemiological studies revealed that $80 \%$ of Parkinson's disease patients have impaired glucose metabolism. Moreover, diabetes can increase the risk of developing Parkinson's disease in young diabetic individuals by up to $380 \%$, and significantly accelerates the progression of both motor and cognitive deficits in Parkinson's disease patients ${ }^{44-46}$. However, the molecular mechanisms underlying this correlation are still unclear. One of the major outcomes of type- 2 diabetes mellitus is the deleterious accumulation of reducing sugars that are unavoidably formed as by-products of essential metabolic processes such as glycolysis ${ }^{47-50}$. Glycation is a nonenzymatic reaction between reducing sugars, such as methylglyoxal (MGO), and biomolecules such as proteins, leading to the formation of mostly-irreversible advanced glycation end products (AGEs) ${ }^{49-51}$. Importantly, the levels of circulating $\mathrm{MGO}$ in type-2 diabetes mellitus patients are 2-4-fold higher than in healthy individuals ${ }^{52-55}$.

Previously, we found that aSyn is glycated in the brains of Parkinson's disease patients and that this modification exacerbates aSyn pathogenicity by promoting its accumulation, oligomerization, aggregation, and toxicity, in vitro and in vivo ${ }^{49,56,57}$.

In this study, we aimed to determine whether generalized glycation in the mouse brain could trigger Parkinson's disease-like features, and to identify the molecular pathways implicated in this process. For this, we delivered MGO via ICV injection in transgenic Thy1-aSyn mice and in corresponding littermates, and evaluated behavioural and biological alterations. We found that MGO exacerbates Parkinson's disease-like motor and non-motor features, alongside with proteomic alterations of glutamatergic components, specifically in the midbrain. In total, our study provides novel mechanistic insight into the connection between metabolic alterations, as those present in type-2 diabetes mellitus, and Parkinson's disease, opening novel avenues for the design of therapeutic interventions.

\section{Materials And Methods}

\section{Methylglyoxal production and standardization}

MGO was synthesized as previously described ${ }^{56,58}$ and purified by fractional distillation. MGO quantification was performed by its derivatization with aminoguanidine ${ }^{59,60}$ (more details in supplementary material).

\section{Animals}

We started by evaluating if glycation contributes to the onset or if it exacerbates Parkinson's disease-like features. For that purpose, we used Thy1-aSyn mice as a model of synucleinopathies. This model recapitulates several features of Parkinson's disease, including aSyn pathology, alterations in nigrostriatal dopaminergic pathway, loss of striatal dopamine and $\mathrm{TH}$, and a progressive neurodegenerative process, with gradual motor and nonmotor deficits ${ }^{61,62}$.

\section{Mice demographics and groups characterization}

The cohort consisted of 27 male Thy1-aSyn and WT littermate mice, distributed among the four experimental groups: vehicle- (1); or MGO-injected (2) WT littermate mice; and vehicle- (3); or MGO-injected (4) Thy1-aSyn mice (Supplementary Fig. $1 \mathrm{~A}$ and B). Vehicle-injected or MGOinjected WT littermate mice group included 5 animals each, with an average age of $16.00 \pm 1.00$ weeks and weight of $29.62 \pm 4.12 \mathrm{~g}$ or $29.01 \pm 3.62 \mathrm{~g}$, respectively (Supplementary Fig. $1 \mathrm{~A}$ and B). Vehicle-injected or MGOinjected Thy1-aSyn mice group was composed of 9 or 8 animals, respectively, with an average age of $16.11 \pm 0.78$ or $16.25 \pm 0.89$ weeks and weight of $28.66 \pm 1.43$ or 28.19 $\pm 2.47 \mathrm{~g}$ (Supplementary Fig. $1 \mathrm{~A}$ and B). Since Thy1-aSyn female mice exhibit much fewer behavioural changes, we decided to only include male mice in our study ${ }^{61,63}$.

\section{Intracerebroventricular injection of MGO and general procedures}

Age-matched 16 weeks old, male transgenic Thy1-aSyn and WT littermates mice received MGO, or vehicle (PBS, $\mathrm{pH}$ 7.4) ICV injection under deep anaesthesia $(80 \mathrm{mg} / \mathrm{kg}$ ketamine hydrochloride, $5 \mathrm{mg} / \mathrm{kg}$ xylazine hydrochloride). Animals were kept anesthetized using isoflurane (2\% - 4\%) and kept at a constant body temperature using a 
conventional heat pad. Briefly, $5 \mu \mathrm{L}$ of MGO (31.6 mM) or PBS were injected into the right lateral ventricle, with the following stereotaxic coordinates, relative to Bregma: Anterior-Posterior (AP) - 0.5 mm, Medial-Lateral (ML) - -1.0 $\mathrm{mm}$, and Dorsal-Ventral (DV) - -2.0 mm. Behavioural testing was performed starting four weeks after surgery. Upon conclusion of the behavioural phenotyping, mice were sacrificed (Supplementary Fig. 1C).

\section{Behavioural tests}

To evaluate the effects of glycation on behaviour, mice underwent a battery of behaviour tests to characterize motor, cognitive, anxiety-related, and olfactory function. Open field test, pole test, rotarod, wire hang test, and adhesive removal test were performed to evaluate motor function. Y maze test was used to assess spatial short-term memory (hippocampal dependent), as a read-out of cognitive function. Anxiety-related behaviour was evaluated with elevated plus maze test. The block test was performed to assess olfactory function. SHIRPA protocol was also used to evaluate general health behaviour. For behavioural tests details, see Supplementary materials.

\section{Immunohistochemistry and counting of neuronal}

\section{populations of mice brain}

After mice sacrifice, the right hemisphere of the brain was transferred into paraformaldehyde (PFA) solution for fixation and immunohistological analysis was performed as previously described ${ }^{56}$. Next, they were cryoprotected in TBS (pH 7.6) containing 30\% sucrose (w/v) overnight at $4^{\circ} \mathrm{C}$. Sagittal free-floating sections $(30 \mathrm{~mm})$ were cut around the region of substantia nigra using a cryostat (Leica CM 3050S, Germany) and, subsequently stained as reported previously ${ }^{64}$. In short, free-floating sections were blocked (5\% Goat Serum (BioWest, France) and 1\% Bovine serum (VWR, USA) and then incubated with different primary antibodies, specifically anti-tyrosine hydroxylase $(\mathrm{TH})$ rabbit (Millipore, 1:1000), anti-aSyn (1:1000, BD Transduction laboratories), anti-NeuN mouse (Millipore, 1:400) overnight at $4^{\circ} \mathrm{C}$. Sections were then washed with TBS and incubated with Alexa Flour 488/555 secondary antibodies (1:1000, Invitrogen). Sections were mounted in SuperFrost ${ }^{\circledR}$ Microscope Slides using Mowiol mounting media (Calbiochem). Omission of the primary antibody resulted in no staining. Image acquisition (10x for a whole brain; 63x and $100 x$ in the substantia nigra region) was performed under a confocal point-scanning microscope using both zstack and scan tile (Zeiss LSM 800 with Airyscan).

Numbers of TH-, DAPI- or NeuN-positive neurons were counted manually, blinded for experimental grouping, using
Cell Counter plugin to mark cells from Fiji open-source software ${ }^{65}$. For each animal within the groups, at least 4 sagittal slices were quantified, and an average used for statistical analysis.

\section{Tissue lysate preparation}

After sacrifice, mice brains were collected and separated into left and right hemispheres. The left hemisphere was dissected into midbrain, striatum, cerebellum, hippocampus, and prefrontal cortex, and rapidly frozen in liquid nitrogen for biochemical analysis. Tissue lysates were prepared as previously described ${ }^{56}$.

\section{SWATH-MS analysis}

A high-throughput proteomics analysis using NanoLC coupled to the TripleTOF 6600 (at UniMS, Mass Spectrometry Unit at $\mathrm{BBET} / \mathrm{ITQB}$ ) was performed to screen for differences in protein expression between experimental groups of midbrain or prefrontal cortex protein extracts. See supplementary materials for sample preparation, information-dependent acquisition runs to generate the spectral library, protein quantification by SWATH-MS and quantitative analysis.

\section{Proteome functional analysis}

Venn diagrams of the statistically differently regulated proteins in midbrain or prefrontal cortex between the experimental groups were used to identify the uniquely affected hits affected in Thy1-aSyn mice injected with MGO using the tool InteractiVenn ${ }^{66}$. These were identified via the comparison between Thy1-aSyn mice injected with MGO and vehicle, excluding the common hits between Thy1-aSyn mice injected with vehicle and the WT mice injected with vehicle (excluding hits generally affected by aSyn expression); and between WT mice injected with MGO vs vehicle (excluding hits generally affected by MGO glycation). Representation of the number of statistically significant up and downregulated hits was performed in Graphpad Prism V9 volcano plots. Protein-protein functional associations were retrieved from STRING (http://www.string-db.org/, version 11.0) ${ }^{67}$. We used the online Enrichr tool (http://www.amp.pharm.mssm.edu/Enrichr/) for the functional enrichment analysis, including Kyoto Encyclopaedia of Genes and Genomes (KEGG) and Gene Ontology (GO) resources ${ }^{68}$. Pathways were obtained from "KEGG 2019 Mouse" and GO terms from "GO Biological Process 2018", "GO Molecular Function 2018", and "GO Cellular Component 2018". Top 7 pathways or GO terms with the highest - $\log 10$ Fisher exact test $p$-value were 
selected ( $p$ values bellow 0.05). Heatmaps representing the differently regulated proteins per top 3 KEGG pathways were done in GraphPad Prism version 9. Protein-protein functional associations representations were colour-coded according to the top KEGG and GO analysis in STRING (Search Tool for the Retrieval of Interacting Genes/Proteins) ${ }^{67,69-78}$. The minimum required interaction score was defined for high confidence (0.7) and disconnected nodes in the network were hidden.

\section{Immunoblot analysis}

These procedures were performed as previously. For more details, see extended material and methods. Proteins were probed using $\mathrm{N}^{\varepsilon}$-carboxyethyl lysine (CEL) (Mouse Anti- $\mathrm{N}^{\varepsilon}$-carboxyethyl lysine, Cosmo-Bio, USA), aSyn (Purified Mouse Anti- $\alpha$-Synuclein antibody, BD Biosciences; San Jose, CA, USA), and $\beta$-actin (Mouse Monoclonal anti- $\beta$ actin antibody Ambion, Thermo Fisher Scientific; Waltham, MA, USA).

\section{Statistical analysis}

Each experimental group was composed at least of five mice, unless stated otherwise, and all values are expressed as normalized means plus standard deviation. Statistical analysis was performed using GraphPad Prism version 9. One-way ANOVA were used to compare differences among conditions and groups, followed by Dunnett's multiple comparison test. Values of $p<0.05$ were considered significant.

\section{Results}

\section{MGO potentiates motor deficits and accelerates colonic dysfunction in Thy1-aSyn mice}

First, in order to establish a baseline, we applied a battery of motor tests in order to characterize the motor behaviour of the animals used in the study (20 weeks-old animals). The open field test was performed to evaluate general motor activity, gross locomotor activity, and exploration habits ${ }^{79}$. The vertical pole test and rotarod were aimed at assessing locomotor activity, motor coordination and balance ${ }^{79-82}$. To evaluate balance and grip strength, the wire hang test was conducted ${ }^{79,83}$. The adhesive removal test was performed to evaluate sensory and motor deficits related to the paw and the mouth ${ }^{84}$. Finally, we also assessed the motor function using SHIRPA protocol tests, mainly the hindlimb clasping test, and colonic function (assessed during open field test) ${ }^{80,85}$.
Vehicle-injected transgenic Thy1-aSyn mice required more time to turn down on the vertical pole (2.1-fold increase) than WT littermates but displayed no significant differences in the time of climbing down or in the total time to perform the task (Fig. 1A-C). Thy1-aSyn mice also showed a decreased latency to fall in the rotarod at both stationary (3.1-fold decrease) or accelerated rotation (1.9-fold decrease) (Fig. 1D and E) when compared to WT littermates. Impairments were also apparent in grip strength evaluated in the wire hang test, with a decreased latency to fall (3.1-fold decrease) (Supplementary Fig. 1D), and in the hindlimb clasping test, showing increased score when compared to WT littermate mice (Fig. 1F). We observed no sensorimotor differences, in the adhesive removal test (Supplementary Fig. 1E), no alterations of locomotor behaviour, assessed by open field (Supplementary Fig. 1F-J), and no differences in colonic function, given by the number of faecal pellets dropped in an open field in 10 minutes (Fig. 1G).

Next, we assessed the effect of MGO injection and found that Thy1-aSyn mice required more time to turn down on the vertical pole compared to vehicle-injected Thy1-aSyn mice (1.3-fold increase), vehicle-injected WT mice (2.7-fold increase) and MGO-injected WT mice (2.4fold increase) (Fig. 1A). No changes in the time to climb down were observed (Fig. 1B). However, MGO-injected Thy1-aSyn mice took more time to complete this task when compared to vehicle-injected WT mice (1.6-fold increase) or to MGO-injected WT mice (2-fold increase), but not to vehicle-injected Thy1-aSyn mice (Fig. 1C). Rotarod performance was also worse in MGO-injected Thy1-aSyn mice, evaluated at a steady rotation of the rod (2.9-fold decrease of latency to fall), when compared to vehicleinjected Thy1-aSyn mice (Fig. 1D). At accelerated rotation, no differences were observed (Fig. 1E). Finally, MGOinjected Thy1-mice showed worst performance in the hindlimb clasping test (Fig. 1F), and worst colonic function, with a smaller number of faecal pellets, when comparing with vehicle-injected WT mice (Fig. 1G). One the other hand, MGO treatment did not significantly change the grip strength (Supplementary Fig. 1D) sensorimotor function (adhesive test Supplementary Fig. 1E), or locomotor activity, assessed by the open field test (Supplementary Fig. 1F-J) when compared to vehicle-injected Thy1-aSyn mice. MGO treatment of WT littermates had no effect in all behavioural tests performed (Fig. 1A-K, Supplementary Fig. 1D-L). 


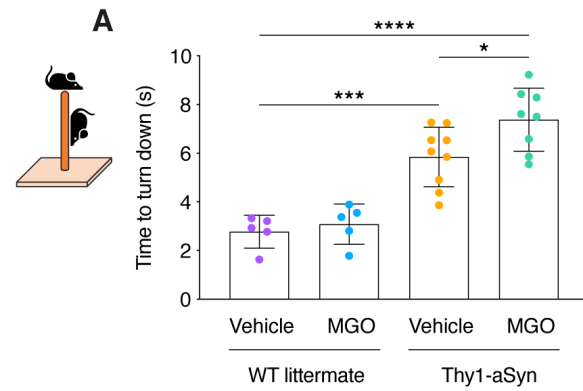

D

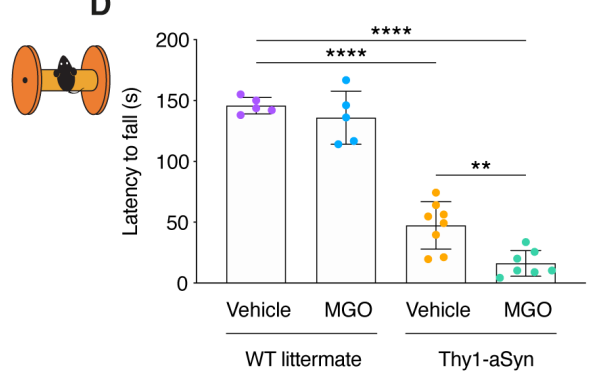

G
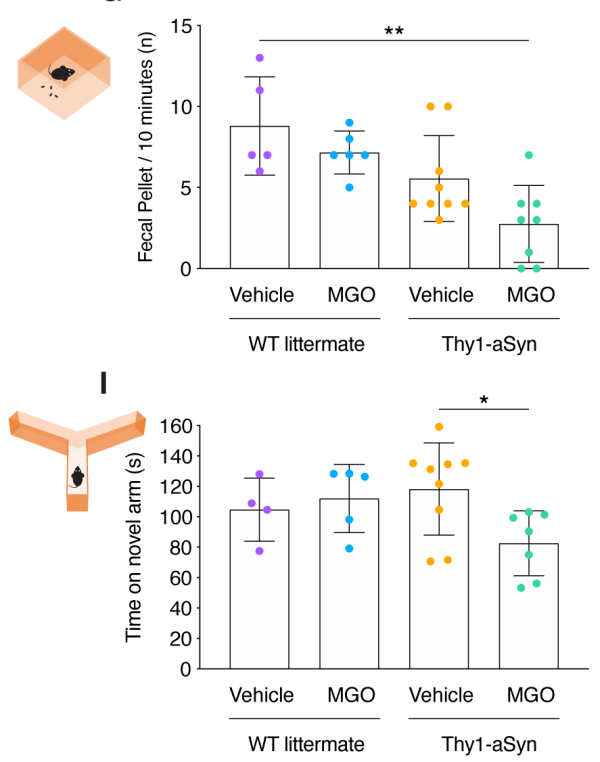

B

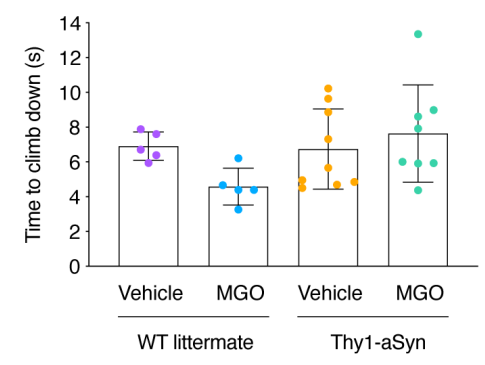

E

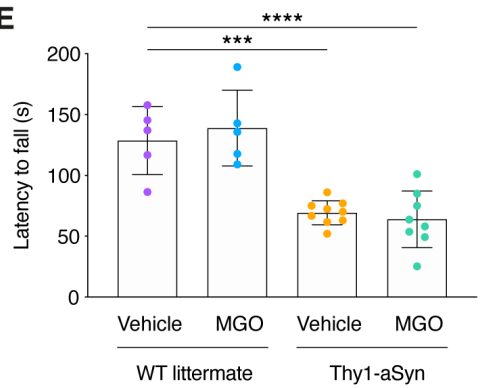

H

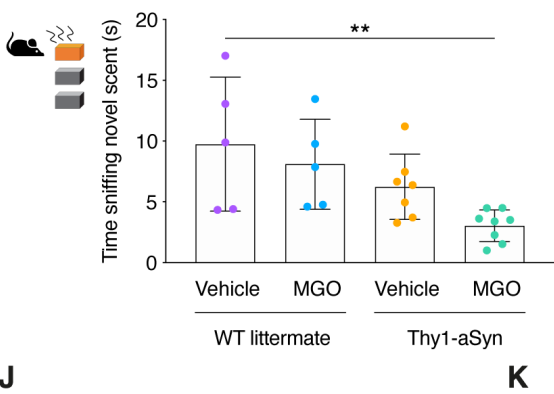

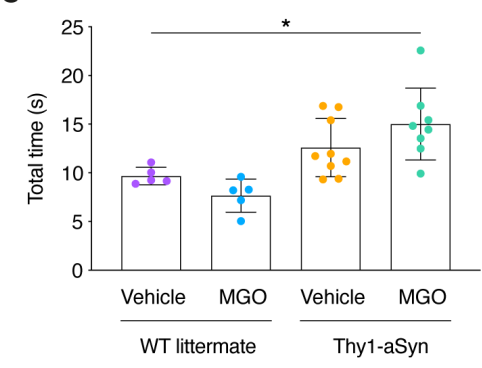

F

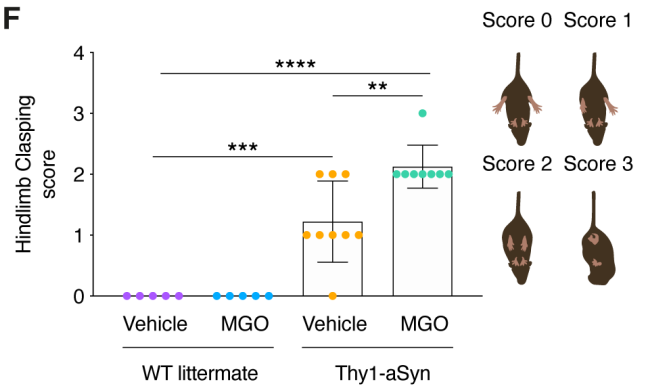

Figure 1. Glycation induces motor dysfunction, cognitive impairment, olfactory, and colonic disturbances in Thy1-aSyn mice. Wild-type littermate (WT) and Thy1-aSyn transgenic (Tg) mice received an intracerebroventricular (ICV) injection of MGO or vehicle (PBS) at 16 weeks of age. Behavioural testing started 4 weeks post-surgery. Plot representations of: pole test - (A) time to turn down (B) time to climb down, (C) total time; rotarod - (D) stationary protocol, (E) acceleration protocol; (F) hindlimb clasping score; (G) faecal pellet production; (H) block test time sniffing novel scent; $Y$ maze test - (I) time on novel arm, (J) number of entries, (K) alternative behaviour. At least $n=5$ in all groups, Ordinary one-way ANOVA, ${ }^{*} p<0.05,{ }^{* *} p<0.01,{ }^{* * *} p<0.001,{ }^{* * * *} p<0.0001$.

\section{MGO aggravates cognitive and olfactory}

\section{disturbances in Thy1-aSyn mice}

Next, we assessed the occurrence of Parkinson's disease-associated non-motor features in the different animal groups ${ }^{7,9-11}$. The $Y$ maze test was performed to assess spatial reference memory, as a read-out of cognitive function 86,87 . Anxiety-related behaviour was evaluated using the elevated plus maze test ${ }^{88,89}$. Olfactory function was assessed using the block test that evaluates sensitivity to social smells, olfactory acuity, and discrimination ${ }^{90,91}$.
At 20 weeks, Thy1-aSyn mice did not show alterations in the block test (Fig. 1H), Y maze test (Fig. 1I-K), and elevated plus maze (Supplementary Fig. 1K-L) when compared to WT littermates. Likewise, MGO injection did not alter the performance of WT mice in these tests (Fig. $1 \mathrm{H}-\mathrm{K}$ and Supplementary Fig. 1 F-L). In contrast, MGO-injected Thy1aSyn mice spent less time sniffing the novel scent (3.2-fold decrease), comparing to vehicle-injected WT mice (Fig. 1H). In addition, MGO-injected Thy1-aSyn mice spent less time (1.4-fold decrease) in the novel arm in the $Y$ maze test (Fig. 1I), comparing to vehicle-injected Thy1-aSyn mice. No 
bioRxiv preprint doi: https://doi.org/10.1101/2021.08.24.457507; this version posted August 25, 2021. The copyright holder for this preprint (which was not certified by peer review) is the author/funder, who has granted bioRxiv a license to display the preprint in perpetuity. It is made available under aCC-BY-NC-ND 4.0 International license.

A

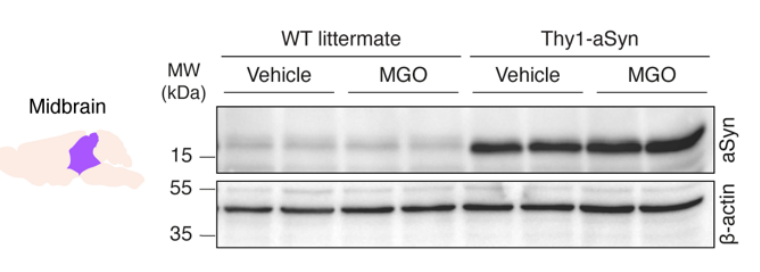

C

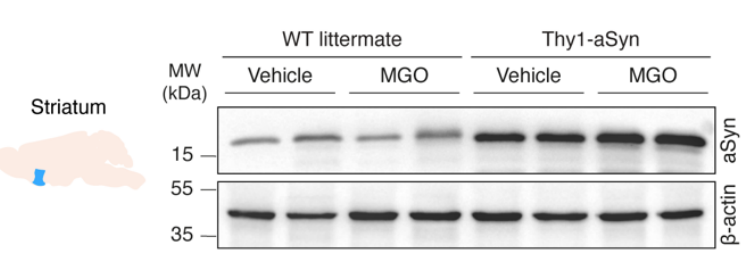

E

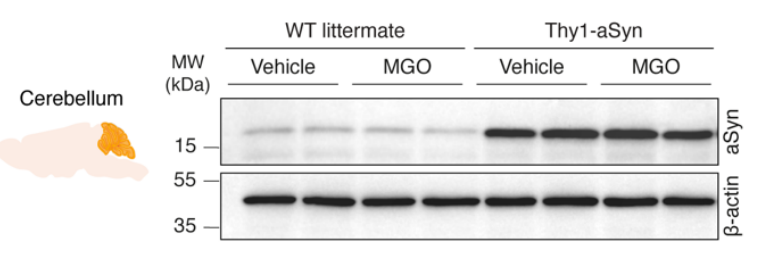

G

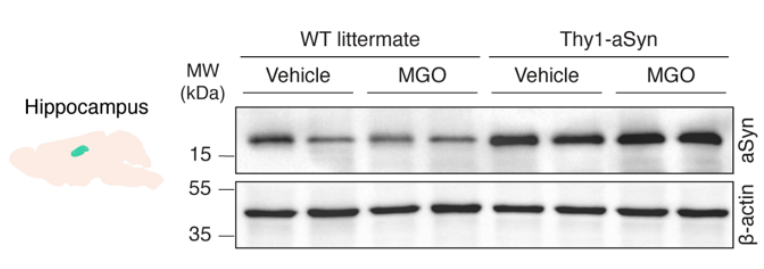

I

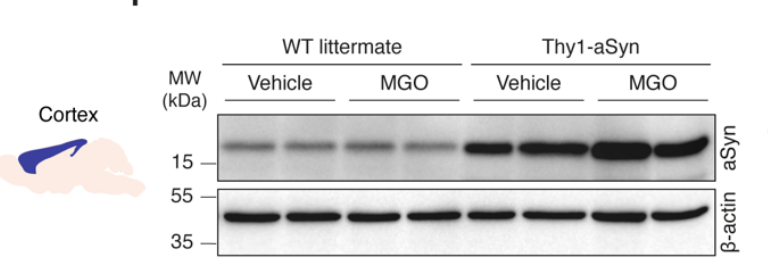

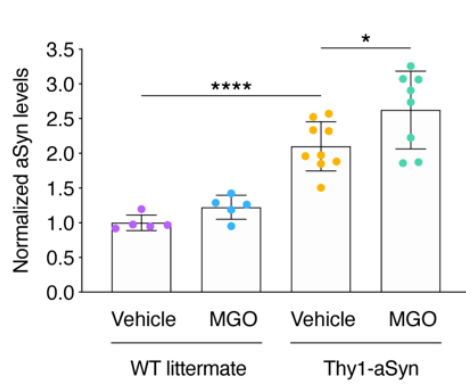
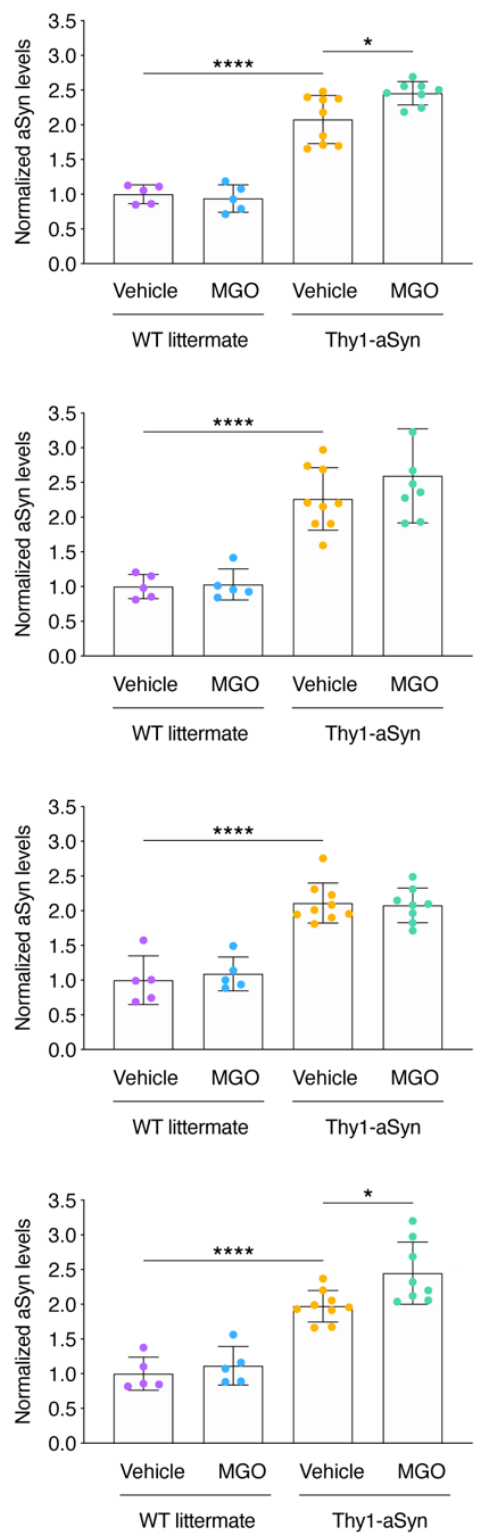

B

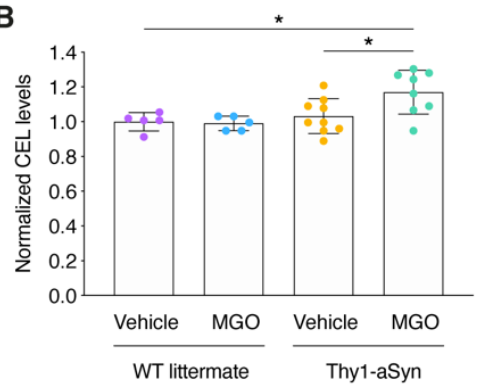

D

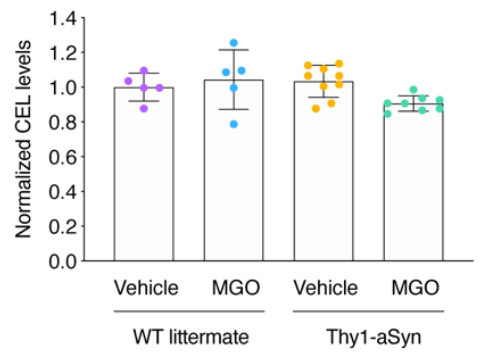

F

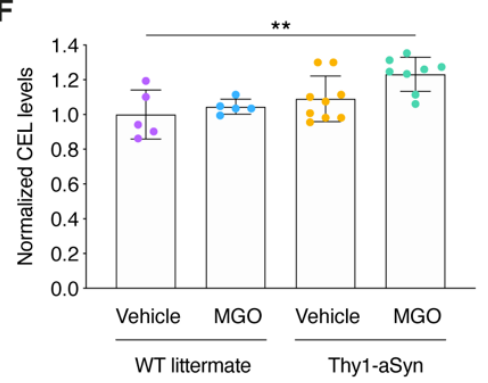

H
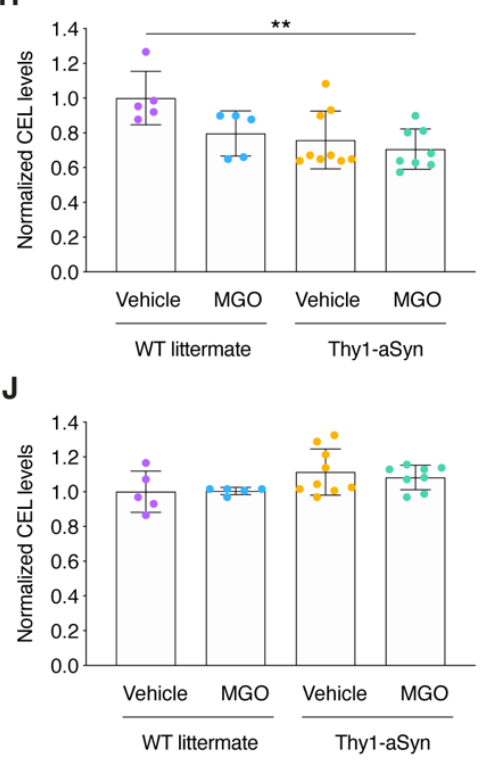

Figure 2. Glycation induces the accumulation of aSyn and AGEs in the midbrain. Wild-type littermate (WT) and Thy1-aSyn transgenic mice received an intracerebroventricular (ICV) injection of MGO or vehicle (PBS) and protein brain extracts from several regions analysed 5 weeks post-injection. Protein extracts were resolved by SDS-PAGE or loaded into membranes in a dotblot system (see Supplemental Figure 2). Membranes were probed with anti-aSyn, anti-CEL and anti- $\beta$-actin for normalization. Representative blots showing 2 samples from each experimental group are shown for aSyn, and densitometric analysis represented for aSyn and CEL in (A, B) midbrain, (C, D) striatum, (E, F) cerebellum, $(\mathbf{G}, \mathbf{H})$ hippocampus, and $(\mathbf{I}, \mathrm{J})$ prefrontal cortex, respectively. At least $n=5$ in all groups, Ordinary one-way ANOVA, ${ }^{*} p<0.05, * * p$ $<0.01, * * * * p<0.0001$. 
bioRxiv preprint doi: https://doi.org/10.1101/2021.08.24.457507; this version posted August 25, 2021. The copyright holder for this preprint (which was not certified by peer review) is the author/funder, who has granted bioRxiv a license to display the preprint in perpetuity. It is made available under aCC-BY-NC-ND 4.0 International license.

differences were observed in anxiety-related behaviour (Supplementary Fig. 1K-L).

Altogether, we observed that MGO exacerbates motor deficits and triggers or anticipates colonic, cognitive, and olfactory disturbances in aSyn-overexpressing mice. We also confirmed that 20 weeks-old Thy1-aSyn mice display impaired motor performance, without colonic, cognitive or olfactory disturbances, compared to WT littermate animals.

\section{MGO potentiates the accumulation of aSyn in the} midbrain, striatum, and prefrontal cortex, and of AGEs in the midbrain of Thy1-aSyn mice

After the behavioural analyses, animals were sacrificed, and the brains were analysed. The left hemisphere was collected and dissected into midbrain, striatum, cerebellum, prefrontal cortex, and hippocampus, and these regions were analysed by immunoblotting. Protein extracts were probed for aSyn and $\beta$-actin, for normalization.
Interestingly, MGO-injected Thy1-aSyn mice presented higher levels of aSyn in the midbrain (1.2-fold increase) (Fig. 2A), striatum (1.2-fold increase) (Fig. 2C), and prefrontal cortex (1.2-fold increase) (Fig. 2I) in comparison to vehicleinjected Thy1-aSyn mice.

To understand the possible sustained effects of protein glycation, we measured the levels of CEL, an MGO-derived AGE. MGO-injected Thy1-aSyn mice showed higher levels of CEL, comparing to both vehicle-injected Thy1-aSyn (1.1-fold increase) and to vehicle or MGO-injected WT mice (1.2-fold increase) in the midbrain (Fig. 2B). In the cerebellum, no significant differences were found, except when comparing MGO-injected Thy1-aSyn mice to vehicle-injected WT mice (1.2-fold increase) (Fig. 2F). Strikingly, the hippocampus displayed decreased levels of CEL in both vehicle- and MGOinjected Thy1-aSyn mice (1.3- and 1.4-fold decrease, respectively) in comparison to vehicle-injected WT animals, suggesting that this region might be protected from glycation (Fig. 2H).
A

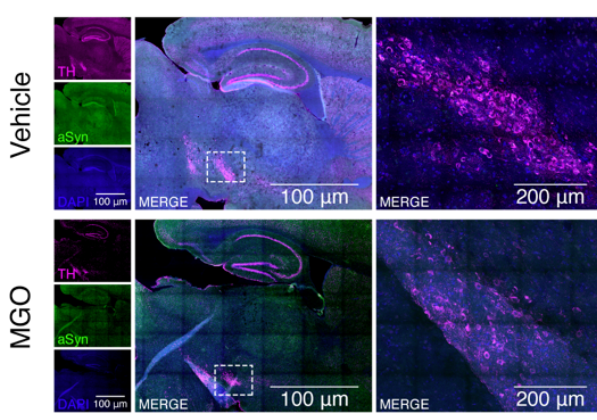

C
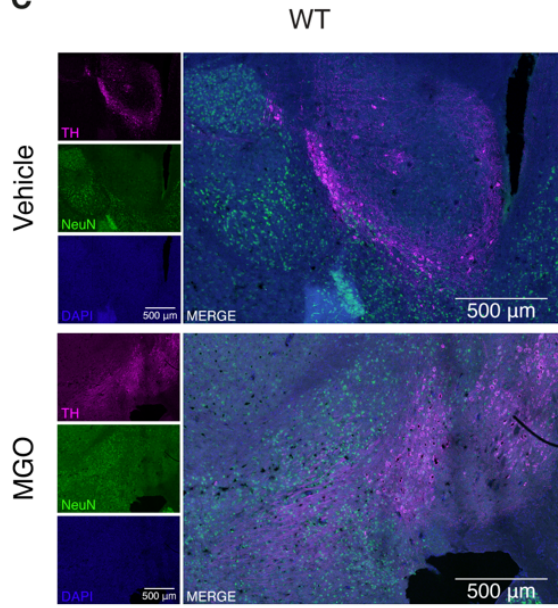

Thy1-aSyn

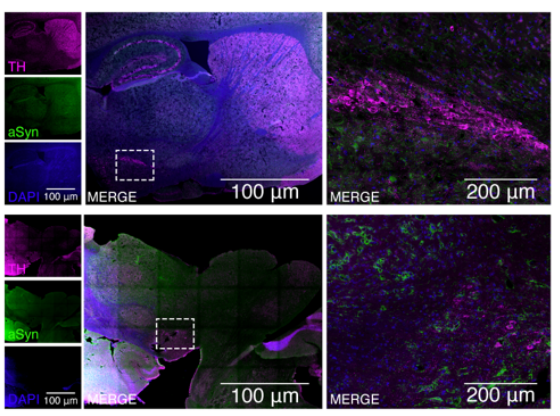

Thy1-aSyn

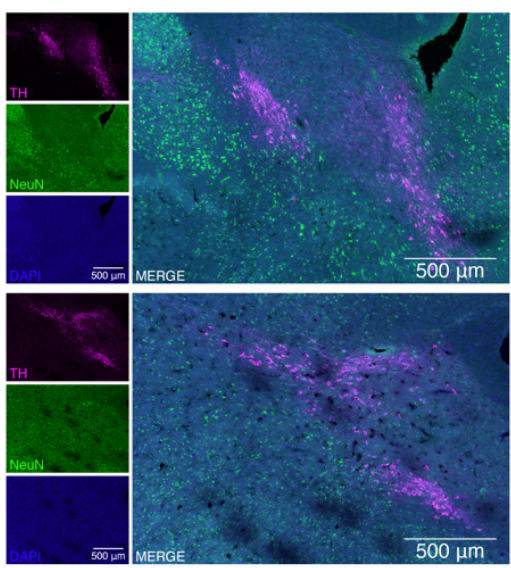

D
B
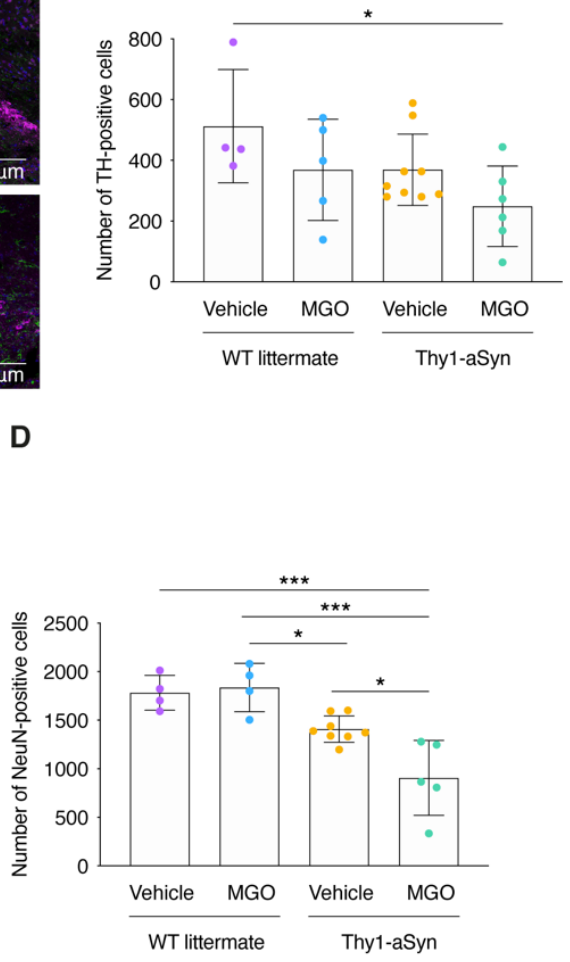

Figure 3. Glycation induces the loss of TH and NeuN neurons in the SNpc. Wild-type littermate (WT) and Thy1-aSyn transgenic mice received an intracerebroventricular (ICV) injection of MGO or vehicle (PBS). (A) Representative micrographs of brain sections immunostained for TH (magenta), aSyn (green), and DAPI (blue). Merge signal is shown. Scale bar $=100 \mu \mathrm{m}$. Depicted area of substantia nigra (dashed square) is shown. Scale bar $=200 \mu \mathrm{m}$. (B) The number of TH-positive cells per experimental group is shown. (C) Representative micrographs of brain sections of the substantia nigra immunostained for TH (magenta), NeuN (green), and DAPI (blue). Merge signal is shown. Scale bar $=500 \mu m$. (D) The number of NeuN-positive cells per experimental group is shown. At least $n=4$ in all groups, Ordinary one-way ANOVA, ${ }^{*} p<0.05, * * * p$ $<0.001$. 
As expected, Thy1-aSyn mice presented a 2.1-fold increase in the levels of aSyn in the midbrain, striatum, and hippocampus, and 1.8- and 2.3-fold increase in the prefrontal cortex and cerebellum, respectively, in comparison to WT littermates (Fig. 2). MGO-injected WT mice had no differences in the levels of aSyn or CEL in comparison to vehicle-injected WT mice (Fig. 2).

\section{MGO triggers neuronal and dopaminergic loss in Thy1-aSyn mice}

Next, we compared the number of dopaminergic neurons and of general neuronal population at SNpc surrounding area via immunohistochemical analysis (stereology).

Vehicle-injected Thy1-aSyn mice did not show differences in the population of $\mathrm{TH}$ - and NeuN-positive neurons when compared to vehicle-injected WT littermates (Fig. 3A-D). In contrast, MGO-injected Thy1-aSyn mice showed lower number of TH-positive neurons, when compared to vehicle-injected WT littermates (2.1-fold decrease) (Fig. 3B).

addition, MGO-injected Thy1-aSyn mice also had lower number of NeuN-positive neurons in comparison to vehicleinjected Thy1-aSyn mice (1.6-fold) and to both vehicle and MGO-injected WT littermates (2.0-fold decrease) (Fig. 3D).

These findings suggest that MGO treatment results in selective neuronal loss in the SNpc and surrounding midbrain regions of Thy1-aSyn mice.

\section{Proteomic analysis of differentially regulated proteins}

To identify the pathways and molecular mechanisms that are dysregulated upon MGO injection, we performed a proteomic analysis using total protein extracts from the midbrain and prefrontal cortex of 5 animals per group (Thy1-aSyn and WT mice injected with vehicle or MGO). SWATH-based MS was performed, and the MS data matched with a customized library of MS/MS spectra created from LC-ESI-MS analysis of brain protein extracts of animals from each group. Each of the 5 samples per group was analysed 3 times. A total of 2153 proteins were identified for a peptide confidence level of $>99 \%$, FDR threshold of $1 \%$. For the quantitative analysis, an initial outlier analysis was performed. The points removed were then replaced with mean values of the analysed group, and iBAQ was normalized. ANOVA analysis between the experimental groups of each brain region was performed to identify the differently regulated proteins.
The response to MGO was followed by comparing MGOinjected with vehicle-injected animals. In the midbrain, 457 proteins were found to be differently regulated between vehicle-injected and MGO-injected WT mice, while 350 proteins were differently present between vehicle-injected and MGO-injected Thy1-aSyn mice. In the prefrontal cortex, 206 proteins were found to be altered by MGO injection in WT mice, and 172 in Thy1-aSyn mice.

The comparison between vehicle-injected Thy1-aSyn and WT mice, revealed the response of the brain proteome to the overexpression of aSyn. Interestingly, we found that 454 proteins were altered in the midbrain, and 256 proteins were altered in the prefrontal cortex of asynoverexpressing animals.

\section{Proteins uniquely-altered by MGO in aSyn transgenic animals}

Next, we identified targets specifically-induced by MGO. To this end, we used a Venn diagram analysis representing the comparisons that enabled us to exclude the general effects of MGO (WT mice injected with MGO vs vehicle) and of aSyn (vehicle-injected Thy1-aSyn vs WT mice), as presented in and for midbrain (Fig. 4A) and prefrontal cortex (Fig. 5A). We found that 160 target proteins were altered as a specific response to MGO treatment in the midbrain, and 105 in the prefrontal cortex of Thy1-aSyn mice. From these, 125 proteins are upregulated, and 35 proteins are downregulated in the midbrain, whereas in the prefrontal cortex 53 proteins are upregulated while 52 are downregulated (Fig. 4B and 5B). By comparing the specific response in the midbrain and prefrontal cortex, we found that only 18 proteins were commonly affected in both regions, suggesting that $M G O$ elicited region-specific alterations.

MGO induces alterations in glutamatergic systemrelated proteins in the midbrain of Thy1-aSyn mice

Upon functional enrichment analysis, we found that the KEGG pathway mostly affected by MGO in the midbrain of Thy1-mice was the glutamatergic synapse. This was followed by amphetamine addiction, by long-term potentiation. Strikingly, these three pathways share several common proteins (Fig. 4C and D). We found that MGO mainly induced the increase in the levels of proteins related with glutamate production, transport, and its respective transporters and receptors (Fig. 4D).

Consistently with the changes identified in glutamatergic synapses, the most affected GO molecular function was the glutamate receptor binding, and the second most affected GO cellular component was the ionotropic glutamate receptor complex (Fig. 4C). The major 
bioRxiv preprint doi: https://doi.org/10.1101/2021.08.24.457507; this version posted August 25, 2021. The copyright holder for this preprint (which was not certified by peer review) is the author/funder, who has granted bioRxiv a license to display the preprint in perpetuity. It is made available under aCC-BY-NC-ND 4.0 International license.

A

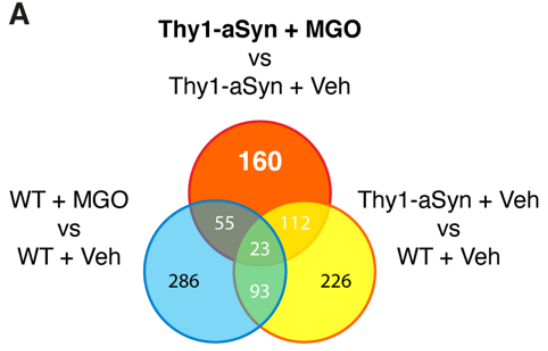

B

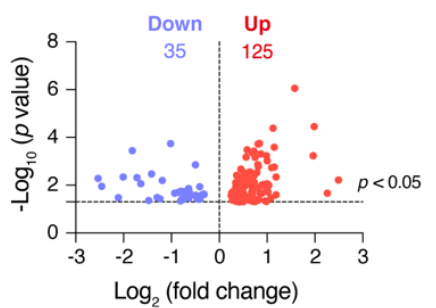

D

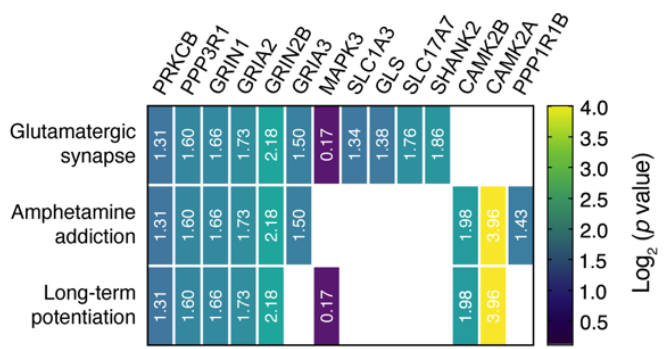

C

Biological Process

Pyruvate metabolic process (GO:0006090)

Regulation of dendritic spine development (GO:0060998)
Phosphate-containing compound metab. proc. (GO:000679 $)$ )

Peptidyl-threonine phosphorylation (GO:0018107)

Positive reg. of protein localization to P.M. (GO:1903078)

Neuron projection development (GO:0031175)

Excitatory postsynaptic potential (GO:0060079)

Molecular Function

Glutamate receptor binding (GO:0035254)

Calmodulin-dep. protein kinase activity (GO:0004683)

Ionotropic glutamate receptor activity (GO:0004970)

Oxidoreductase activity (GO:0016616)

Nucleotide kinase activity (GO:0019201)

Protein phosphatase 2B binding (GO:0030346)

Cadherin binding (GO:0045296)

Cellular Component

Mitochondrion (GO:0005739)

Ionotropic glutamate receptor complex (GO:0008328)

Fcolin-1-rich granule (GO:0101002)

Focal adhesion (GO:0005925)

Fcolin-1-rich granule lumen (GO:1904813)

Cytoskeleton (GO:0005856)

Actin cytoskeleton (GO:0015629)

KEGG Pathway

Glutamatergic synapse

Amphetamine addiction

Long-term potentiation

cAMP signalling pathway

Circadian entrainment

Dopaminergic synapse

Nicotine addiction

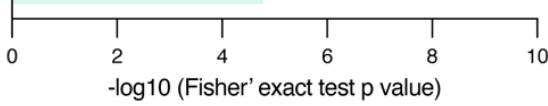

E

\begin{tabular}{rr|l} 
Down & \multicolumn{1}{|c}{ Up } \\
& 0 & 5 \\
& 0 & 4 \\
6796) & 1 & 7 \\
& 0 & 5 \\
0 & 4 \\
2 & 5 \\
0 & 3 \\
& 0
\end{tabular}

E

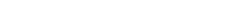


bioRxiv preprint doi: https://doi.org/10.1101/2021.08.24.457507; this version posted August 25, 2021. The copyright holder for this preprint (which was not certified by peer review) is the author/funder, who has granted bioRxiv a license to display the preprint in perpetuity. It is made available under aCC-BY-NC-ND 4.0 International license.

A

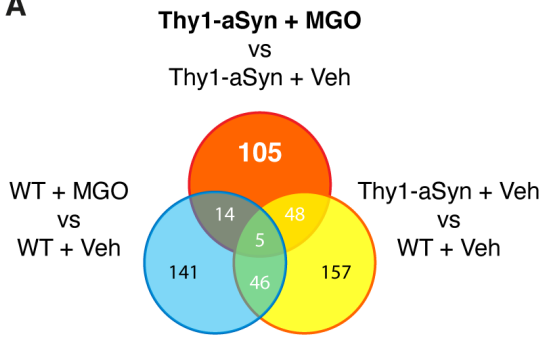

C

Biological Process

Respiratory electron transport chain (GO:0022904)

Translation (GO:0006412)

Ephrin receptor signalling pathway (GO:0048013)

Fc-y receptor signall. pathway - phagocytosis (GO:0038096)

FC-y receptor signalling pathway (GO:0038094)

Fc receptor mediated stimulatory signal. path. (GO:0002431)

Mitoch. ATP synth. coupled electr. transp. (GO:0042775)

Molecular Function

Actin filament binding (GO:0051015)

NADH dehydrogenase - quinone (GO:0050136)

NADH dehydrogenase - ubiquinone (GO:0008137)

Purine ribonucleoside triphosphate binding (GO:0035639)

Cadherin binding (GO:0045296)

Actin binding (GO:0003779)

GTP binding (GO:0005525)

Cellular Component

Focal adhesion (GO:0005925)

Actin cytoskeleton (GO:0015629)

Mitochondrion (GO:0005739)

Secretory granule lumen (GO:0034774)

Ficolin-1-rich granule lumen (GO:1904813)

Ficolin-1-rich granule (GO:0101002)

Cytoplasmic vesicle lumen (GO:0060205)

KEGG Pathway

Non-alcoholic fatty liver disease (NAFLD)

Alzheimer's disease

Bacterial invasion of epithelial cells

Huntington's disease

Oxidative phosphorylation

Fc gamma R-mediated phagocytosis

Parkinson's disease

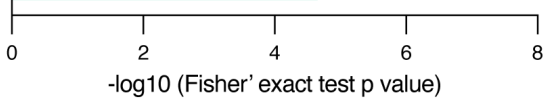

B

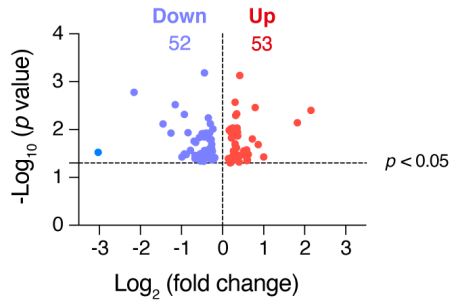

D

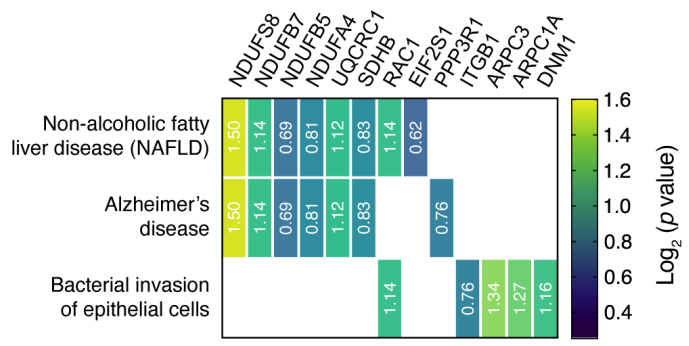

E

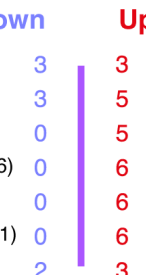

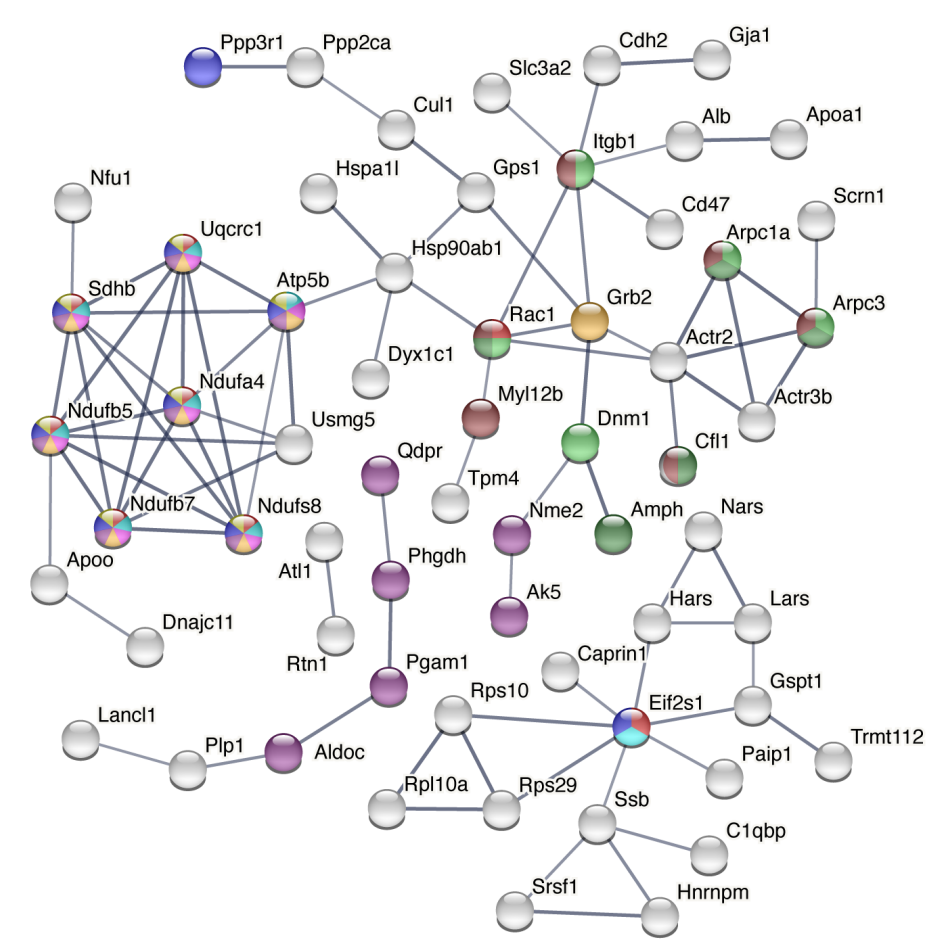

NAFLD Alzheimer's disease Bacterial invasion of epithelial cells $\bigcirc$ Huntington's disease

Oxidative phosphorylation $\mathrm{Fc}$ r R-mediated phagocytosis $\bigcirc$ Parkinson's disease

Thermogenesis Metabolic pathways $\bigcirc$ Regulation of actin cytoskeleton

Figure 5. Glycation alters components of the respiratory electron transport chain in the prefrontal cortex of Thy1-aSyn mice. Proteomic differences between cortical proteins from WT or Thy1-aSyn mice injected with vehicle or MGO. (A) Venn diagram depicting unique and shared midbrain proteome between pairwise comparisons of Thy1-aSyn mice injected with MGO and vehicle, Thy1-aSyn mice and WT mice both injected with vehicle and WT mice injected with MGO and vehicle. (B) Volcano plot for unique hits of Thy1-aSyn mice injected with MGO and Vehicle. Statistically significant down and upregulated hits are presented. (C) KEEG pathways and gene ontology GO terms analysis is presented, depicting the number of down and upregulated unique hits. Distribution of -log10 (Fisher exact test $p$ value) is shown. (D) Heatmap of the uniquely altered proteins corresponding to the top 3 altered KEGG pathways. (E) Protein-protein interaction networks of uniquely altered proteins, extracted from the STRING 11.0 database. Only the proteins that are interacting within a network are show. KEGG pathways or GO Biological processes are colour coded.

epithelial cells pathways (Fig. 5C and D). Strikingly, the hits related to NAFLD, Alzheimer's disease, Huntington's disease, oxidative phosphorylation, and Parkinson's disease, corresponded to a group of proteins involved in the respiratory electron transport chain (Fig. 5C-E). NADH dehydrogenase [ubiquinone] 1 beta subcomplex subunit 7 (NDUFB7, Ndufb7), NADH dehydrogenase [ubiquinone] iron-sulphur protein 8, mitochondrial (NDUFS8, Ndufs8) and Cytochrome b-c1 complex subunit 1, mitochondrial (UQCRC1, Uqcrc1), were upregulated (Fig. 5D). In contrast, cytochrome c oxidase subunit NDUFA4 (Ndufa4), NADH dehydrogenase [ubiquinone] 1 beta subcomplex subunit 5 , mitochondrial (NDUFB5, Ndufb5), and succinate dehydrogenase [ubiquinone] iron-sulphur subunit, mitochondrial (SDHB, SdhB), were downregulated. 
Other unique hits and interconnected proteins were associated with actin filament binding, purine ribonucleoside triphosphate binding, cadherin binding processes, Fc $\gamma$ receptor mediated phagocytosis or to metabolic pathway (Fig. 5C and E).

\section{Discussion}

Synucleinopathies are a group devastating neurodegenerative diseases for which disease-modifying therapies are missing. The misfolding, accumulation, and aggregation of aSyn, a common hallmark among the various synucleinopathies, is thought to be a key event in the neurodegenerative process. However, our poor understanding of the molecular mechanisms underlying neurodegeneration has hampered our ability to develop effective therapies.

The cardinal motor features of Parkinson's disease result from the loss of dopaminergic neurons in the SNpc, and the consequent depletion of dopamine in the striatum. The degeneration of dopaminergic neurons is believed to be, somehow, associated with the aggregation of aSyn ${ }^{20-22}$. Mutations and polymorphisms have been linked to familiar forms of Parkinson's disease ${ }^{92,93}$, but account for only 5$10 \%$ of $\operatorname{cases}^{94,95}$, suggesting that an interplay between genetics and environmental factors account for the vast majority of cases.

Type-2 diabetes mellitus has emerged as an important risk factor for various neurodegenerative disorders and, in particular for Parkinson's disease $42-44,46,49,50$. Epidemiological studies revealed a strong association between type-2 diabetes mellitus and the risk for developing Parkinson's disease ${ }^{44}$. Importantly, type-2 diabetes mellitus accelerates the progression of both motor and cognitive deficits in Parkinson's disease patients ${ }^{44-46}$. However, the molecular mechanisms underlying the connection between the two diseases remains poorly understood. Type-2 diabetes mellitus is a chronic metabolic disease known for glucose metabolism imbalance, and is characterized by hyperglycaemia, insulin resistance, and impaired glucose tolerance ${ }^{45,47,96}$. Remarkably, glycation, a major molecular outcome of type-2 diabetes mellitus, has also been implicated in several neurodegenerative disorders. We found that glycation modulates the pathogenicity of both aSyn and huntingtin, central players in Parkinson's disease and in Huntington's disease, respectively ${ }^{56,97}$. Moreover, several studies showed that glycation also plays a role in Alzheimer's disease ${ }^{98-100}$. Given that protein aggregation is a common hallmark among different neurodegenerative disorders, we posit that glycation may modulate the aggregation and toxicity of the different aggregation-prone proteins and that it may unveil novel targets for therapeutic intervention.

In this study, we investigated how glycation contributes to the dysfunction of neuronal pathways implicated in synucleinopathies, and how it contributes to the onset of Parkinson's disease-like phenotypes.

To explore our hypothesis, 16 weeks-old Thy1-aSyn or WT littermate mice received a single dose of $160 \mathrm{nmol}$ of MGO or vehicle via ICV injection. In a previous study, we evaluated the impact of an acute delivery of MGO directly to the SNpc or to the striatum ${ }^{56}$. Although several aSynassociated phenotypes were identified, that experimental procedure was based on the delivery of MGO directly into the brain regions mostly affected in Parkinson's disease. Here, we applied more physiological amount of MGO (4.5times lower than previously) and used ICV injection in order to obtain a more homogeneous distribution of MGO in the central nervous system ${ }^{101-104}$. The amount of MGO used corresponds to reported levels of this glycating agent in the mouse brain (approximately 60-130 nmol/brain) ${ }^{105}$. Importantly, the amount used is significantly lower (4 to more than 100 times) than those used in other studies using ICV-delivery ${ }^{105-108}$.

We performed a detailed behavioural characterization of the animals 4 weeks after ICV injection and, 5 weeks postinjection, animals were sacrificed and brains were collected for biochemical, immunohistochemical and SWATH-MS analysis. The choice of this timeline was based on the reported onset of behavioural alterations in Thy1-aSyn mice $^{61}$.

\section{MGO injection aggravates Parkinson's disease like behavioural alterations}

Previous reports indicate that most Parkinson's diseaselike behavioural features in Thy1-aSyn mice start at the age of 28 weeks $^{61}$, although they may also exhibit earlier motor deficits $^{109}$. In our experimental conditions, 20 weeks-old Thy1-aSyn mice already presented reduced performance on the vertical pole test, rotarod and wire hang test, and increased hindlimb clasping score ${ }^{109}$. At this stage, no colonic, cognitive, olfactory, and anxiety-related alterations were observed. Therefore, our cohort displayed several alterations that are typically observed at 28 weeks. Moreover, these Thy1-aSyn mice already presented a higher motor impairment in the rotarod test than usual (24 months of age $)^{110}$. In contrast, although Thy1-aSyn mice are reported to be more anxious and to present olfactory alterations at 12 weeks of age, we did not confirm these features in our experimental cohort ${ }^{90,111}$. In agreement with 
previous reports, no cognitive deficits were observed on the y maze test, as they commonly appear in mice between 2836 weeks of age ${ }^{111}$.

Following the protocol described, we found that MGO injection in Thy1-aSyn mice aggravates motor deficits as observed in the vertical pole test, rotarod and hindlimb clasping test. Moreover, MGO injection accelerates cognitive impairment in Thy1-aSyn mice, as this was only described to occur between the age of 28 and 36 weeks ${ }^{111}$. In contrast to vehicle-treatment, MGO injection in Thy1aSyn mice also anticipated the onset of colonic and olfactory disturbances, comparing to vehicle-injected WT animals, assessed in the open field and block test, respectively. These behavioural alterations suggest that MGO accelerates and aggravates disease progression in aSyn-overexpressing mice. In the experimental conditions used, although some tendencies are observed, MGO treatment did not alter the behavioural phenotypes of WT mice. In the future, to test whether glycation triggers Parkinson's disease-like phenotypes, it will be of interest to design a study to assess the effect of chronic exposure to MGO in WT animals.

\section{MGO elicits aSyn accumulation and neuronal loss in the midbrain}

Our biochemical analysis of different brain regions of interest in the context of Parkinson's disease showed that MGO-injected Thy1-aSyn mice display increased levels of aSyn in the midbrain, striatum, and prefrontal cortex. This may account for the behavioural alterations observed ${ }^{112-114}$. In agreement with the glycating potential of MGO, we observed an accumulation of AGEs in the midbrain of MGOinjected Thy1-aSyn mice, when comparing to vehicleinjected Thy1-aSyn and to both WT groups.

Chemicals delivered via ICV injection reach various brain regions, including the prefrontal cortex, striatum, hypothalamus, hippocampus, midbrain, and medulla ${ }^{115}$. Although the local concentration of the injected chemical may differ from region to region, the areas surrounding the ventricles should be exposed to higher concentrations of the chemicals, in contrast to subarachnoid areas. Therefore, it was striking to observe that the midbrain was the only region displaying a significant increase of MGOglycated proteins. Since the striatum and hippocampus should also be exposed to MGO, this finding suggests that either the proteostasis network in the midbrain is less effective in clearing dysfunctional glycated proteins than other brain regions, or that the midbrain is more susceptible to carbonyl-stress. These hypothesis are consistent with the significant decrease in the number of both TH- and NeuN-positive neurons in the SNpc of MGOinjected Thy1-aSyn mice in comparison to vehicle-injected WT mice which, in turn, may account for the observed decrease in motor performance 27,29-31. $^{\text {. }}$

\section{MGO mainly impacts glutamatergic pathway in} the midbrain and oxidative phosphorylation pathway in the prefrontal cortex

Using our proteomics approach, we determined that the response to MGO-injection differs between prefrontal cortex and midbrain. From the uniquely dysregulated proteins specifically induced by glycation in Thy1-aSyn mice, only 18 proteins are commonly dysregulated between the prefrontal cortex and the midbrain. Moreover, the impact of $\mathrm{MGO}$ in the midbrain affects a larger number of proteins (350) than in the prefrontal cortex (172), for the same total amount of detected proteins. Although MGO increased the levels of aSyn in both regions, the differences may be due to a distinct exposure to MGO, as AGEs accumulated in the midbrain, but not in the prefrontal cortex. Another possibility is that this may also be the result of a higher susceptibility of midbrain cells to MGO, as previously suggested.

MGO glycation is known to trigger the unfolded protein response, to impair oxidative metabolism, to drive mitochondrial dysfunction, and to impact on the oxidative stress response $49,50,116,117$. Several of these consequences are intrinsically related with the depletion of cellular defences against oxidative stress since reduced glutathione and NADPH are shared cofactors to cope with both oxidative stress response and with the detoxification of MGO by glyoxalases and aldose reductases ${ }^{49,50}$. This is particularly relevant in neurons, which are more vulnerable to MGO due to their lower capacity to detoxify this compound, particularly when compared to astrocytes ${ }^{118,119}$. Failure in its detoxification results in increased glycation of several proteins, particularly in the mitochondria ${ }^{120}$. In fact, neuronal mitochondrial damage is well established, and is known to suppress oxygen consumption, decrease the activity of respiratory chain complexes, and the capacity of energy production, increasing the production of reactive oxygen species (ROS) ${ }^{121,122}$. Importantly, mitochondrial dysfunction in the dopaminergic neurons is associated with Parkinson's disease ${ }^{123,124}$. Thy1-aSyn mice injected with MGO displayed severe dysregulation of oxidative phosphorylation in the prefrontal cortex. Several elements of mitochondrial complex I were dysregulated, with a decrease of NDUFB5 and increase of both NDUFB7 and NDUFS8. Moreover, components of complex II (SDHB) and complex IV (NDUFA4) were decreased, while a component 
bioRxiv preprint doi: https://doi.org/10.1101/2021.08.24.457507; this version posted August 25, 2021. The copyright holder for this preprint (which was not certified by peer review) is the author/funder, who has granted bioRxiv a license to display the preprint in perpetuity. It is made available under aCC-BY-NC-ND 4.0 International license.

of complex III (UQCRC1) was increased. These findings suggest that increased levels of MGO in the brain may contribute to mitochondrial dysfunction in the cortical area.
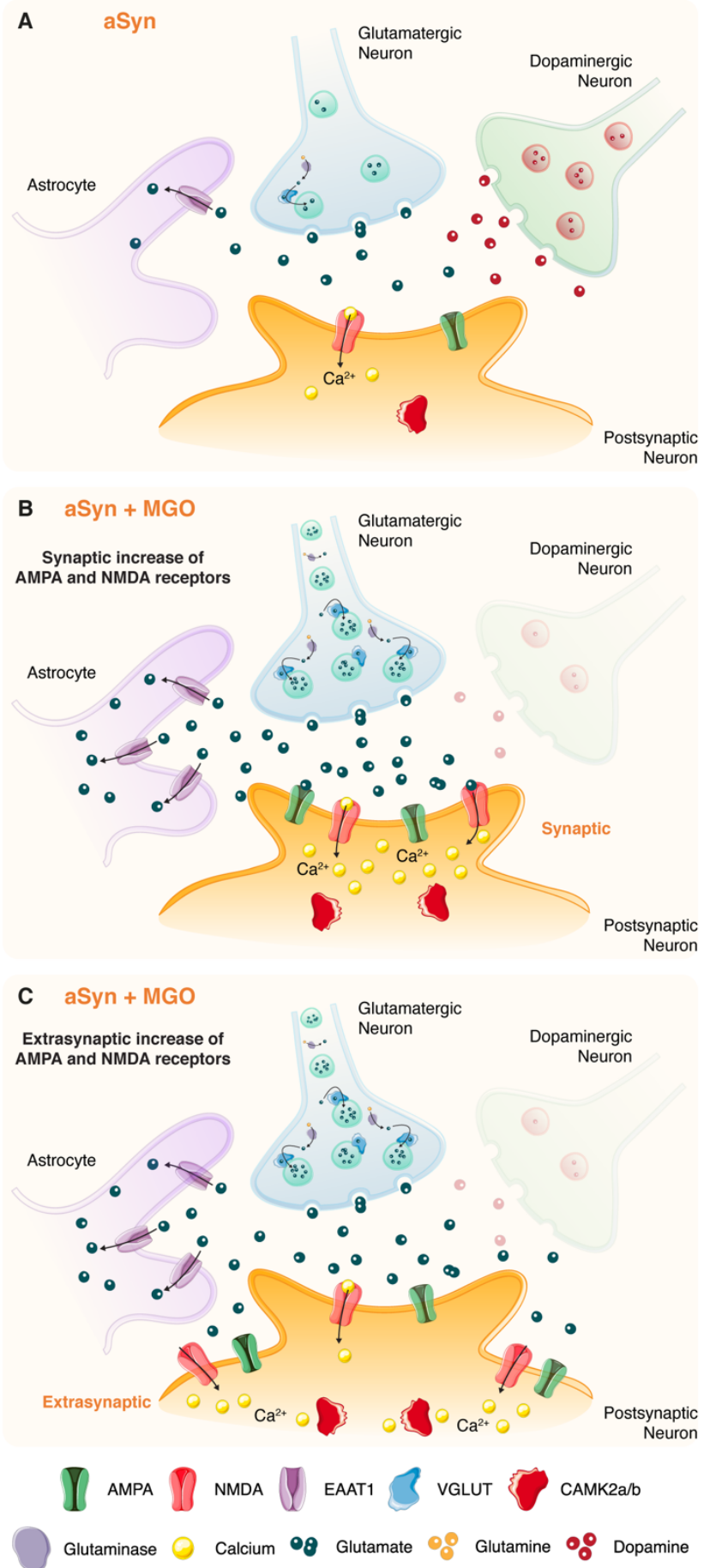

Figure 6. Effects of MGO in the midbrain of Thy1-aSyn mice. The diagram depicts the MGO-altered glutamatergic proteins in the midbrain of Thy1-aSyn mice. Schematic of dopaminergic and glutamatergic signalling in (A) vehicle-injected mice, (B) and (C) MGO-injected mice. While in (A) vehicle-injected mice, basal dopaminergic and glutamatergic signalling should occur, (B) and (C) MGO-injected mice present a smaller number of dopaminergic synapses. (B) and (C) Proteomics data suggest a probable increase of glutamate production (glutaminase) and packaging in glutamatergic vesicles (VGLUT), the release of glutamate to the synaptic cleft and astrocytic reuptake (EAAT1) or entry to the postsynaptic neuron via AMPA or NMDA receptors. The increase of these receptors may occur at the (B) synapse or (C) extrasynaptically, inducing calcium entry to the cell. An increase of both CAMK2a and CAMK2b is also observed, supporting the hypothesis of enhanced glutamatergic signalling. A strong imbalance in the post-synaptic levels of calcium can occur and contribute to excitotoxic events.

Altered glutamatergic firing has been described in Parkinson's disease and is believed to be caused by the dopamine depletion in the striatum ${ }^{27-31}$. The SNpc is highly rich in NMDA, AMPA and metabotropic glutamate receptors, and glutamate or glutamate-dopamine neurons are intermixed with midbrain dopaminergic neurons ${ }^{34-36}$. In the midbrain of MGO-injected Thy1-aSyn mice, we observed a generalized loss of neurons, and a specific loss of dopaminergic neurons. Moreover, we found that several uniquely dysregulated proteins in the midbrain of MGOinjected mice belong to the glutamatergic pathway, which may reflect a possible increase of glutamatergic signalling. Specifically, there was an increase of the levels of glutaminase and VGLUT1. These events suggest a probable increase in the presynaptic production of glutamate, and of its storage in glutamatergic vesicles (Fig. 6). The levels of astrocytic EAAT1 were also increased and this protein is classically responsible for the rapid removal of released glutamate from the synaptic cleft ${ }^{125,126}$. This finding further supports the hypothesis that glutamate production and release are increased in this brain region upon $M G O$ insult. Moreover, a generalized increase of AMPA (GRIA2 and GRIA3) and NMDA (GRIN1 and GRIN2B) receptors was observed, most probably at the post-synaptic neuron (Fig. $6 \mathrm{~B}$ and $\mathrm{C}$ ). In particular, we observed an increase of the GRIN2B, a subunit of NMDA receptor that is generally linked to cell death signalling ${ }^{127,128}$, and is typically more abundant early in development, shifting to GRIN2A during development ${ }^{128}$. Our study does not allow us to resolve whether the increased levels of these glutamate receptor subunits are at the post-synaptic membrane (Fig. 6B), extrasynaptically (Fig. 6C), or at the cytosol. Nevertheless, several post-synaptic glutamatergic targets are also increased, including the calcineurin subunit B type 1, PPP1R1B, PKC $\beta$, and SHANK2, suggesting increased glutamatergic activity. In fact, we also found an increase in the levels of CAMK2A and CAMK2B in MGO-injected Thy1aSyn mice, which are known to promote the trafficking and transient translocation of AMPA receptors to the postsynaptic membrane ${ }^{129}$. Together with the observation of decreased levels of MAPK3/ERK2, these findings suggest an impairment of LTP $^{130}$, as we previously reported ${ }^{129}$. Excessive release of glutamate may also activate 
extrasynaptic glutamate receptors. Oligomeric aSyn, may not only induce increased release of glutamate from astrocytes, but also activate extrasynaptic NMDA receptors, and this process may lead to synaptic loss. Importantly, the specific extrasynaptic NMDA receptor antagonist NitroSynapsin protects from these deleterious effects of oligomerized aSyn ${ }^{131}$. Independently of the localization of glutamate receptors, excessive glutamate may trigger apoptotic cell death because of intracellular calcium overload upon receptor stimulation, and is a common hallmark of neurodegenerative diseases ${ }^{132}$.

Based on our findings, we cannot distinguish whether the alteration in glutamatergic signalling precedes dopaminergic degeneration or is a consequence of dopaminergic dysregulation in MGO-injected Thy1-aSyn mice. In a first scenario, MGO could exert a direct effect that elicits glutamatergic hyperactivity, causing an excitotoxic phenomenon that triggers general neuronal degeneration and specific dopaminergic loss. Dopamine depletion would explain the cardinal features of Parkinson's disease, and are consistent with the motor alterations we observed. In agreement with this hypothesis, we observed the accumulation of aSyn in the midbrain, and we previously reported that MGO-treatment increases both aSyn glycation and oligomerization ${ }^{56}$. Moreover, we further reported that prolonged exposure to aSyn oligomers drives to the long-lasting increase of basal glutamatergic synaptic transmission ${ }^{129}$. In fact, aSyn oligomers may activate NMDA receptors, increasing the basal levels of intracellular calcium and recruiting AMPA receptors to the membrane ${ }^{129}$. In a second scenario, MGO could first trigger the loss of dopaminergic neurons, possibly due to the enhanced accumulation aSyn. In an indirect process, the brain may respond to dopamine depletion by increasing glutamatergic firing in the midbrain. This compensatory mechanism should enhance the release of dopamine from the surviving dopaminergic neurons to maintain dopamine homeostasis. It is presently unclear if the glutamatergic alterations cause or exacerbate neurodegeneration in patients with Parkinson's disease. However, glutamatergic hyperactivity may prompt an excitotoxic cascade further promoting neurodegeneration ${ }^{37,132}$, which would ultimately lead to the observed behavioural alterations. Importantly, alterations in glutamate content in the brain of Parkinson's disease patients have been reported by several clinical studies using magnetic resonance imaging (MRI), positron emission tomography (PET) and single photon emission computed tomography (SPECT), consistent with increased glutamate neurotransmission ${ }^{133-135}$. Moreover, increased levels of glutamate in the plasma of Parkinson's disease patients have been reported, further reflecting increased cerebral glutamatergic activity ${ }^{136,137}$. Alterations in this glutamatergic transmission contribute to the pathophysiology of dyskinesias, impaired motor coordination and motor fluctuations ${ }^{28,138-142}$. Additionally, dysfunction of glutamate metabolism is also implicated in non-motor features of Parkinson's disease, including depression and cognitive impairment ${ }^{143-145}$.

\section{Conclusions}

The pathogenesis of Parkinson's disease and the mechanisms leading to the accumulation and aggregation aSyn remain poorly understood. Type-2 diabetes mellitus is an important risk factor for Parkinson's disease and, interestingly, glycation mediates aSyn pathogenesis in vitro and in animal models. In this study, we demonstrate that glycation exacerbates Parkinson's disease-like motor and non-motor features in Thy1-aSyn mice. Importantly, these behavioural alterations are followed by the accumulation of aSyn in the midbrain, striatum, and prefrontal cortex, and by neuronal loss in the midbrain. Furthermore, we found that MGO-injected Thy1-aSyn mice show pronounced alterations in proteins of the glutamatergic pathway within the midbrain, consistent with increased production of glutamate and increased glutamatergic transmission. Thus, we suggest that in conditions of aSyn pathology, MGO induces glutamatergic hyperactivity in the midbrain directly, or indirectly by depleting dopaminergic neurons, which aggravates both motor and non-motor features in mice $^{40,138}$.

In conclusion, we uncovered a major role for MGOderived glycation in the exacerbation or anticipation of Parkinson's disease-like features, suggesting that antidiabetic/anti-glycation agents hold promise as diseasemodifying agents in Parkinson's disease. Likewise, glutamatergic-silencing molecules may suppress excitotoxic events that underlie neuronal degeneration in synucleinopathies.

\section{Author contributions}

AC, JEC, PGA, LVL, TFO, and HVM designed research; AC, JEC, MG, MTF, IMM, BFG, BMA, RAG, LS performed research; PRF prepared and provided materials; BMA, RGA and RM made statistical analysis of proteomic data; $A C$, BMA, RAG and HVM performed proteomic analysis; $A C$ and HVM analysed all data; AC and HVM wrote the manuscript. All authors reviewed the manuscript. 


\section{Acknowledgements}

We would like to acknowledge the vivarium and behavioural facilities at Instituto de Medicina Molecular João Lobo Antunes for all the support. We also acknowledge Prof. Rosalina Fonseca, Prof. Sílvia V. Conde, Prof. Rita Machado de Oliveira, Dr. Natália Madeira, Dr. Liliana Lopes, Dr. Tatiana Burrinha, and Dr. Catarina Perdigão for fruitful discussions. We acknowledge Dr. Manuela Correia for all the laboratory support.

\section{Funding}

This study was supported by Fundação para a Ciência e Tecnologia (FCT) PTDC/NEU-OSD/5644/2014, iNOVA4Health UID/Multi/04462/2013 and Sociedade Portuguesa de Diabetologia. Authors were supported by: AC (FCT, PD/BD/136863/2018; ProRegeM - PhD programme, mechanisms of disease and regenerative medicine); LS (SFRH/BD/143286/2019; PhD Studentship); BFG (PTDC/NEU-OSD/5644/2014). TFO is supported by the Deutsche Forschungsgemeinschaft (DFG, German Research Foundation) under Germany's Excellence Strategy - EXC 2067/1- 390729940, and by SFB1286 (B8).

\section{Competing interests}

The authors have no conflicts of interest to declare.

\section{Supplementary material}

Supplementary material includes Extended Material and Methods and Supplementary Figures 1-4.

\section{References}

1. Spillantini MG, Schmidt ML, Lee VM, Trojanowski JQ, Jakes R, Goedert M. Alpha-synuclein in Lewy bodies. Nature 1997; 388(6645): 839-40.

2. Weinreb PH, Zhen W, Poon AW, Conway KA, Lansbury PT, Jr. NACP, a protein implicated in Alzheimer's disease and learning, is natively unfolded. Biochemistry 1996; 35(43): 13709-15.

3. Vekrellis K, Xilouri M, Emmanouilidou E, Rideout HJ, Stefanis L. Pathological roles of alpha-synuclein in neurological disorders. The Lancet Neurology 2011; 10(11): 1015-25.
4. Puschmann A, Bhidayasiri R, Weiner WJ. Synucleinopathies from bench to bedside. Parkinsonism Relat Disord 2012; 18 Suppl 1: S24-7.

5. Goedert $M$, Jakes $R$, Spillantini MG. The Synucleinopathies: Twenty Years On. J Parkinsons Dis 2017; 7(s1): S51-s69.

6. Dickson DW. Parkinson's disease and parkinsonism: neuropathology. Cold Spring Harbor perspectives in medicine 2012; 2(8).

7. Goldman JG, Postuma R. Premotor and nonmotor features of Parkinson's disease. Current opinion in neurology 2014; 27(4): 434-41.

8. Sveinbjornsdottir S. The clinical symptoms of Parkinson's disease. Journal of neurochemistry 2016; 139 Suppl 1: 318-24.

9. Pfeiffer RF. Non-motor symptoms in Parkinson's disease. Parkinsonism Relat Disord 2016; 22 Suppl 1: S119-22.

10. Schapira AHV, Chaudhuri KR, Jenner P. Non-motor features of Parkinson disease. Nature reviews Neuroscience 2017; 18(7): 435-50.

11. Vicente Miranda H, Cassio R, Correia-Guedes L, Gomes MA, Chegao A, Miranda E, et al. Posttranslational modifications of blood-derived alpha-synuclein as biochemical markers for Parkinson's disease. Sci Rep 2017; 7(1): 13713.

12. Iwai A, Masliah E, Yoshimoto M, Ge N, Flanagan L, de Silva HA, et al. The precursor protein of non-A beta component of Alzheimer's disease amyloid is a presynaptic protein of the central nervous system. Neuron 1995; 14(2): 467-75.

13. Maroteaux L, Campanelli JT, Scheller RH. Synuclein: a neuron-specific protein localized to the nucleus and presynaptic nerve terminal. J Neurosci 1988; 8(8): 2804-15.

14. McLean PJ, Ribich S, Hyman BT. Subcellular localization of alpha-synuclein in primary neuronal cultures: effect of missense mutations. Journal of neural transmission Supplementum 2000(58): 53-63.

15. Soto $C$. Unfolding the role of protein misfolding in neurodegenerative diseases. Nature reviews Neuroscience 2003; 4(1): 49-60.

16. Oueslati A, Fournier M, Lashuel HA. Role of posttranslational modifications in modulating the structure, function and toxicity of alpha-synuclein: implications for Parkinson's disease pathogenesis and therapies. Progress in brain research 2010; 183: 11545.

17. Uversky VN. Neuropathology, biochemistry, and biophysics of alpha-synuclein aggregation. Journal of neurochemistry 2007; 103(1): 17-37. 
18. Spillantini MG, Crowther RA, Jakes R, Cairns NJ, Lantos $\mathrm{PL}$, Goedert M. Filamentous alpha-synuclein inclusions link multiple system atrophy with Parkinson's disease and dementia with Lewy bodies. Neuroscience letters 1998; 251(3): 205-8.

19. Spillantini MG, Crowther RA, Jakes R, Hasegawa M, Goedert M. alpha-Synuclein in filamentous inclusions of Lewy bodies from Parkinson's disease and dementia with lewy bodies. Proc Natl Acad Sci U S A 1998; 95(11): 6469-73.

20. Kalia LV, Lang AE. Parkinson's disease. Lancet (London, England) 2015; 386(9996): 896-912.

21. Poewe W, Seppi K, Tanner CM, Halliday GM, Brundin $P$, Volkmann J, et al. Parkinson disease. Nature reviews Disease primers 2017; 3: 17013.

22. Lashuel HA, Overk CR, Oueslati A, Masliah E. The many faces of alpha-synuclein: from structure and toxicity to therapeutic target. Nature reviews Neuroscience 2013; 14(1): 38-48.

23. Dickson DW, Braak H, Duda JE, Duyckaerts C, Gasser T, Halliday GM, et al. Neuropathological assessment of Parkinson's disease: refining the diagnostic criteria. The Lancet Neurology 2009; 8(12): 1150-7.

24. Damier P, Hirsch EC, Agid Y, Graybiel AM. The substantia nigra of the human brain. II. Patterns of loss of dopamine-containing neurons in Parkinson's disease. Brain : a journal of neurology 1999; 122 ( Pt 8): 1437-48.

25. Fearnley JM, Lees AJ. Ageing and Parkinson's disease: substantia nigra regional selectivity. Brain : a journal of neurology 1991; 114 ( Pt 5): 2283-301.

26. Benazzouz A, Mamad O, Abedi P, Bouali-Benazzouz R, Chetrit J. Involvement of dopamine loss in extrastriatal basal ganglia nuclei in the pathophysiology of Parkinson's disease. Frontiers in aging neuroscience 2014; 6: 87.

27. Calabresi P, Picconi B, Tozzi A, Ghiglieri V, Di Filippo M. Direct and indirect pathways of basal ganglia: a critical reappraisal. Nat Neurosci 2014; 17(8): 1022-30.

28. Sgambato-Faure $V$, Cenci MA. Glutamatergic mechanisms in the dyskinesias induced by pharmacological dopamine replacement and deep brain stimulation for the treatment of Parkinson's disease. Progress in neurobiology 2012; 96(1): 69-86.

29. Masoud ST, Vecchio LM, Bergeron Y, Hossain MM, Nguyen LT, Bermejo MK, et al. Increased expression of the dopamine transporter leads to loss of dopamine neurons, oxidative stress and I-DOPA reversible motor deficits. Neurobiol Dis 2015; 74: 66-75.

30. Rodriguez-Oroz MC, Jahanshahi M, Krack P, Litvan I, Macias R, Bezard E, et al. Initial clinical manifestations of Parkinson's disease: features and pathophysiological mechanisms. The Lancet Neurology 2009; 8(12): 1128-39.

31. Bernheimer $\mathrm{H}$, Birkmayer W, Hornykiewicz O, Jellinger $\mathrm{K}$, Seitelberger $\mathrm{F}$. Brain dopamine and the syndromes of Parkinson and Huntington. Clinical, morphological and neurochemical correlations. J Neurol Sci 1973; 20(4): 415-55.

32. Wichmann T, DeLong MR. Pathophysiology of parkinsonian motor abnormalities. Adv Neurol 1993; 60: 53-61.

33. Greenamyre JT, Porter RH. Anatomy and physiology of glutamate in the CNS. Neurology 1994; 44(11 Suppl 8): S7-13.

34. Root DH, Wang HL, Liu B, Barker DJ, Mód L, Szocsics P, et al. Glutamate neurons are intermixed with midbrain dopamine neurons in nonhuman primates and humans. Sci Rep 2016; 6: 30615.

35. Blandini F, Greenamyre JT. Prospects of glutamate antagonists in the therapy of Parkinson's disease. Fundam Clin Pharmacol 1998; 12(1): 4-12.

36. Rodriguez MC, Obeso JA, Olanow CW. Subthalamic nucleus-mediated excitotoxicity in Parkinson's disease: a target for neuroprotection. Ann Neurol 1998; 44(3 Suppl 1): S175-88

37. Bezard E, Boraud T, Bioulac B, Gross CE. Involvement of the subthalamic nucleus in glutamatergic compensatory mechanisms. The European journal of neuroscience 1999; 11(6): 2167-70.

38. Garcia BG, Neely MD, Deutch AY. Cortical regulation of striatal medium spiny neuron dendritic remodeling in parkinsonism: modulation of glutamate release reverses dopamine depletion-induced dendritic spine loss. Cereb Cortex 2010; 20(10): 2423-32.

39. Caudle WM, Zhang J. Glutamate, excitotoxicity, and programmed cell death in Parkinson disease. Exp Neurol 2009; 220(2): 230-3.

40. Albin $R L$, Young $A B$, Penney JB. The functional anatomy of basal ganglia disorders. Trends Neurosci 1989; 12(10): 366-75.

41. Carrillo-Mora P, Silva-Adaya D, Villaseñor-Aguayo K. Glutamate in Parkinson's disease: Role of antiglutamatergic drugs. Basal Ganglia 2013; 3(3): 147-57.

42. Yang YW, Hsieh TF, Li Cl, Liu CS, Lin WY, Chiang JH, et al. Increased risk of Parkinson disease with diabetes mellitus in a population-based study. Medicine (Baltimore) 2017; 96(3): e5921.

43. Hu G, Jousilahti P, Bidel S, Antikainen R, Tuomilehto J. Type 2 diabetes and the risk of Parkinson's disease. Diabetes care 2007; 30(4): 842-7. 
44. Pagano G, Polychronis S, Wilson H, Giordano B, Ferrara $\mathrm{N}$, Niccolini $\mathrm{F}$, et al. Diabetes mellitus and Parkinson disease. Neurology 2018; 90(19): e1654-e62.

45. Athauda D, Foltynie T. Insulin resistance and Parkinson's disease: A new target for disease modification? Progress in neurobiology 2016; 145146: 98-120.

46. Yue $X$, Li H, Yan H, Zhang P, Chang L, Li T. Risk of Parkinson Disease in Diabetes Mellitus: An Updated Meta-Analysis of Population-Based Cohort Studies. Medicine (Baltimore) 2016; 95(18): e3549.

47. Negre-Salvayre A, Salvayre R, Auge N, Pamplona R, Portero-Otin M. Hyperglycemia and glycation in diabetic complications. Antioxidants \& redox signaling 2009; 11(12): 3071-109.

48. Maessen DE, Stehouwer CD, Schalkwijk CG. The role of methylglyoxal and the glyoxalase system in diabetes and other age-related diseases. Clinical science (London, England : 1979) 2015; 128(12): 839-61.

49. Vicente Miranda H, El-Agnaf OM, Outeiro TF. Glycation in Parkinson's disease and Alzheimer's disease. Mov Disord 2016; 31(6): 782-90.

50. Vicente Miranda $H$, Outeiro TF. The sour side of neurodegenerative disorders: the effects of protein glycation. J Pathol 2010; 221(1): 13-25.

51. Munch G, Westcott B, Menini T, Gugliucci A. Advanced glycation endproducts and their pathogenic roles in neurological disorders. Amino acids 2012; 42(4): 122136.

52. Kong X, Ma MZ, Huang K, Qin L, Zhang HM, Yang Z, et al. Increased plasma levels of the methylglyoxal in patients with newly diagnosed type 2 diabetes 2 . J Diabetes 2014; 6(6): 535-40.

53. Lu J, Randell E, Han Y, Adeli K, Krahn J, Meng QH. Increased plasma methylglyoxal level, inflammation, and vascular endothelial dysfunction in diabetic nephropathy. Clin Biochem 2011; 44(4): 307-11.

54. Pastor-Belda M, Fernandez-Garcia AJ, Campillo N, Perez-Carceles MD, Motas M, Hernandez-Cordoba M, et al. Glyoxal and methylglyoxal as urinary markers of diabetes. Determination using a dispersive liquidliquid microextraction procedure combined with gas chromatography-mass spectrometry. J Chromatogr A 2017; 1509: 43-9.

55. Senda M, Ogawa S, Nako K, Okamura M, Sakamoto T, Ito $\mathrm{S}$. The strong relation between post-hemodialysis blood methylglyoxal levels and post-hemodialysis blood glucose concentration rise. Clin Exp Nephrol 2015; 19(3): 527-33.

56. Vicente Miranda H, Szego EM, Oliveira LMA, Breda C, Darendelioglu E, de Oliveira RM, et al. Glycation potentiates alpha-synuclein-associated neurodegeneration in synucleinopathies. Brain : a journal of neurology 2017; 140(5): 1399-419.

57. Vicente Miranda H, Chegao A, Oliveira MS, Fernandes Gomes B, Enguita FJ, Outeiro TF. Hsp27 reduces glycation-induced toxicity and aggregation of alphasynuclein. FASEB J 2020; 34(5): 6718-28.

58. Gomes RA, Sousa Silva M, Vicente Miranda H, Ferreira $A E$, Cordeiro CA, Freire AP. Protein glycation in Saccharomyces cerevisiae. Argpyrimidine formation and methylglyoxal catabolism. Febs J 2005; 272(17): 4521-31.

59. Arai M, Nihonmatsu-Kikuchi N, Itokawa M, Rabbani N, Thornalley PJ. Measurement of glyoxalase activities. Biochem Soc Trans 2014; 42(2): 491-4.

60. Thornalley PJ, Yurek-George A, Argirov OK. Kinetics and mechanism of the reaction of aminoguanidine with the alpha-oxoaldehydes glyoxal, methylglyoxal, and 3-deoxyglucosone under physiological conditions. Biochem Pharmacol 2000; 60(1): 55-65.

61. Chesselet MF, Richter F, Zhu C, Magen I, Watson MB, Subramaniam SR. A progressive mouse model of Parkinson's disease: the Thy1-aSyn ("Line 61") mice. Neurotherapeutics : the journal of the American Society for Experimental NeuroTherapeutics 2012; 9(2): 297-314.

62. Rockenstein $E$, Mallory $M$, Hashimoto $M$, Song $D$, Shults CW, Lang I, et al. Differential neuropathological alterations in transgenic mice expressing alphasynuclein from the platelet-derived growth factor and Thy-1 promoters. Journal of neuroscience research 2002; 68(5): 568-78.

63. Lam HA, Wu N, Cely I, Kelly RL, Hean S, Richter F, et al. Elevated tonic extracellular dopamine concentration and altered dopamine modulation of synaptic activity precede dopamine loss in the striatum of mice overexpressing human alpha-synuclein. Journal of neuroscience research 2011; 89(7): 1091-102.

64. Shvachiy L, Geraldes V, Amaro-Leal A, Rocha I. Intermittent low-level lead exposure provokes anxiety, hypertension, autonomic dysfunction and neuroinflammation. Neurotoxicology 2018; 69: 30719.

65. Schindelin J, Arganda-Carreras I, Frise E, Kaynig V, Longair M, Pietzsch $\mathrm{T}$, et al. Fiji: an open-source platform for biological-image analysis. Nat Methods 2012; 9(7): 676-82.

66. Heberle $H$, Meirelles GV, da Silva FR, Telles GP, Minghim R. InteractiVenn: a web-based tool for the analysis of sets through Venn diagrams. BMC Bioinformatics 2015; 16(1): 169. 
67. Szklarczyk D, Gable AL, Lyon D, Junge A, Wyder S, Huerta-Cepas J, et al. STRING v11: protein-protein association networks with increased coverage, supporting functional discovery in genome-wide experimental datasets. Nucleic Acids Res 2019; 47(D1): D607-D13.

68. Xie Z, Bailey A, Kuleshov MV, Clarke DJB, Evangelista JE, Jenkins SL, et al. Gene Set Knowledge Discovery with Enrichr. Curr Protoc 2021; 1(3): e90.

69. Snel B, Lehmann G, Bork P, Huynen MA. STRING: a web-server to retrieve and display the repeatedly occurring neighbourhood of a gene. Nucleic Acids Res 2000; 28(18): 3442-4.

70. von Mering $C$, Huynen $M$, Jaeggi $D$, Schmidt S, Bork $P$, Snel B. STRING: a database of predicted functional associations between proteins. Nucleic Acids Res 2003; 31(1): 258-61.

71. von Mering $C$, Jensen $L$, Snel B, Hooper SD, Krupp M, Foglierini $M$, et al. STRING: known and predicted protein-protein associations, integrated and transferred across organisms. Nucleic Acids Res 2005; 33(Database issue): D433-7.

72. von Mering C, Jensen $L$, Kuhn M, Chaffron S, Doerks $T$, Krüger $B$, et al. STRING 7--recent developments in the integration and prediction of protein interactions. Nucleic Acids Res 2007; 35(Database issue): D358-62.

73. Jensen $L$, Kuhn $M$, Stark $M$, Chaffron S, Creevey $C$, Muller J, et al. STRING 8--a global view on proteins and their functional interactions in 630 organisms. Nucleic Acids Res 2009; 37(Database issue): D412-6.

74. Szklarczyk D, Franceschini A, Kuhn M, Simonovic M, Roth A, Minguez $P$, et al. The STRING database in 2011: functional interaction networks of proteins, globally integrated and scored. Nucleic Acids Res 2011; 39(Database issue): D561-8.

75. Franceschini A, Szklarczyk D, Frankild S, Kuhn M, Simonovic M, Roth A, et al. STRING v9.1: proteinprotein interaction networks, with increased coverage and integration. Nucleic Acids Res 2013; 41(Database issue): D808-15.

76. Franceschini A, Lin J, von Mering C, Jensen LJ. SVD-phy: improved prediction of protein functional associations through singular value decomposition of phylogenetic profiles. Bioinformatics 2016; 32(7): 1085-7.

77. Szklarczyk D, Franceschini A, Wyder S, Forslund K, Heller D, Huerta-Cepas J, et al. STRING v10: proteinprotein interaction networks, integrated over the tree of life. Nucleic Acids Res 2015; 43(Database issue): D447-52.

78. Szklarczyk D, Morris JH, Cook H, Kuhn M, Wyder S, Simonovic $M$, et al. The STRING database in 2017: quality-controlled protein-protein association networks, made broadly accessible. Nucleic Acids Res 2017; 45(D1): D362-d8.

79. Brooks SP, Dunnett SB. Tests to assess motor phenotype in mice: a user's guide. Nature reviews Neuroscience 2009; 10(7): 519-29.

80. Zhu JW, Li YF, Wang ZT, Jia WQ, Xu RX. Toll-Like Receptor 4 Deficiency Impairs Motor Coordination. Frontiers in neuroscience 2016; 10: 33.

81. Matsuura K, Kabuto H, Makino H, Ogawa N. Pole test is a useful method for evaluating the mouse movement disorder caused by striatal dopamine depletion. Journal of neuroscience methods 1997; 73(1): 45-8.

82. Dunham NW, Miya TS. A note on a simple apparatus for detecting neurological deficit in rats and mice. Journal of the American Pharmaceutical Association American Pharmaceutical Association 1957; 46(3): 208-9.

83. Glynn D, Bortnick RA, Morton AJ. Complexin II is essential for normal neurological function in mice. Human molecular genetics 2003; 12(19): 2431-48.

84. Bouet V, Boulouard M, Toutain J, Divoux D, Bernaudin $M$, Schumann-Bard $P$, et al. The adhesive removal test: a sensitive method to assess sensorimotor deficits in mice. Nature protocols 2009; 4(10): 1560-4.

85. Guyenet SJ, Furrer SA, Damian VM, Baughan TD, La Spada AR, Garden GA. A simple composite phenotype scoring system for evaluating mouse models of cerebellar ataxia. Journal of visualized experiments : JoVE 2010(39).

86. Kraeuter AK, Guest PC, Sarnyai Z. The Y-Maze for Assessment of Spatial Working and Reference Memory in Mice. Methods in molecular biology (Clifton, NJ) 2019; 1916: 105-11.

87. Lalonde R. The neurobiological basis of spontaneous alternation. Neuroscience and biobehavioral reviews 2002; 26(1): 91-104.

88. Komada M, Takao K, Miyakawa T. Elevated plus maze for mice. Journal of visualized experiments : JoVE 2008(22).

89. Walf AA, Frye CA. The use of the elevated plus maze as an assay of anxiety-related behavior in rodents. Nature protocols 2007; 2(2): 322-8.

90. Fleming SM, Tetreault NA, Mulligan CK, Hutson CB, Masliah E, Chesselet MF. Olfactory deficits in mice overexpressing human wildtype alpha-synuclein. The European journal of neuroscience 2008; 28(2): 24756. 
91. Taylor TN, Greene JG, Miller GW. Behavioral phenotyping of mouse models of Parkinson's disease. Behavioural brain research 2010; 211(1): 1-10.

92. Kalinderi K, Bostantjopoulou S, Fidani L. The genetic background of Parkinson's disease: current progress and future prospects. Acta Neurol Scand 2016; 134(5): 314-26.

93. Lesage $S$, Brice A. Parkinson's disease: from monogenic forms to genetic susceptibility factors. Human molecular genetics 2009; 18(R1): R48-59.

94. Tysnes OB, Storstein A. Epidemiology of Parkinson's disease. J Neural Transm (Vienna) 2017; 124(8): 9015.

95. Elbaz A, Carcaillon L, Kab S, Moisan F. Epidemiology of Parkinson's disease. Revue neurologique 2016; 172(1): 14-26.

96. DeFronzo RA, Ferrannini E, Groop L, Henry RR, Herman $\mathrm{WH}$, Holst JJ, et al. Type 2 diabetes mellitus. Nature reviews Disease primers 2015; 1: 15019.

97. Vicente Miranda H, Gomes MA, Branco-Santos J, Breda C, Lazaro DF, Lopes LV, et al. Glycation potentiates neurodegeneration in models of Huntington's disease. Sci Rep 2016; 6: 36798.

98. Angeloni C, Zambonin L, Hrelia S. Role of methylglyoxal in Alzheimer's disease. Biomed Res Int 2014; 2014: 238485.

99. Batkulwar K, Godbole R, Banarjee R, Kassaar O, Williams RJ, Kulkarni MJ. Advanced Glycation End Products Modulate Amyloidogenic APP Processing and Tau Phosphorylation: A Mechanistic Link between Glycation and the Development of Alzheimer's Disease. ACS Chem Neurosci 2018; 9(5): 988-1000.

100. Li XH, Du LL, Cheng XS, Jiang X, Zhang Y, Lv BL, et al. Glycation exacerbates the neuronal toxicity of betaamyloid. Cell Death Dis 2013; 4: e673.

101. Kuo A, Smith MT. Theoretical and practical applications of the intracerebroventricular route for CSF sampling and drug administration in CNS drug discovery research: a mini review. Journal of neuroscience methods 2014; 233: 166-71.

102. Mattis VB, Ebert AD, Fosso MY, Chang CW, Lorson CL. Delivery of a read-through inducing compound, TC007, lessens the severity of a spinal muscular atrophy animal model. Human molecular genetics 2009; 18(20): 3906-13.

103. Passini MA, Watson DJ, Wolfe JH. Gene delivery to the mouse brain with adeno-associated virus. Methods in molecular biology (Clifton, NJ) 2004; 246: 225-36.

104. Passini MA, Wolfe JH. Widespread gene delivery and structure-specific patterns of expression in the brain after intraventricular injections of neonatal mice with an adeno-associated virus vector. Journal of virology 2001; 75(24): 12382-92.

105. Jakubcakova V, Curzi ML, Flachskamm C, Hambsch B, Landgraf $\mathrm{R}$, Kimura $\mathrm{M}$. The glycolytic metabolite methylglyoxal induces changes in vigilance by generating low-amplitude non-REM sleep. Journal of psychopharmacology (Oxford, England) 2013; 27(11): 1070-5.

106. Hambsch B, Chen BG, Brenndorfer J, Meyer M, Avrabos C, Maccarrone G, et al. Methylglyoxalmediated anxiolysis involves increased protein modification and elevated expression of glyoxalase 1 in the brain. Journal of neurochemistry 2010; 113(5): 1240-51.

107. Distler MG, Plant LD, Sokoloff G, Hawk AJ, Aneas I, Wuenschell GE, et al. Glyoxalase 1 increases anxiety by reducing GABAA receptor agonist methylglyoxal. The Journal of clinical investigation 2012; 122(6): 2306-15.

108. Hansen F, Pandolfo P, Galland F, Torres FV, Dutra MF, Batassini C, et al. Methylglyoxal can mediate behavioral and neurochemical alterations in rat brain. Physiology \& behavior 2016; 164(Pt A): 93-101.

109. Fleming SM, Salcedo J, Fernagut PO, Rockenstein E, Masliah E, Levine MS, et al. Early and progressive sensorimotor anomalies in mice overexpressing wildtype human alpha-synuclein. J Neurosci 2004; 24(42): 9434-40.

110. van der Putten $\mathrm{H}$, Wiederhold $\mathrm{KH}$, Probst A, Barbieri S, Mistl C, Danner S, et al. Neuropathology in mice expressing human alpha-synuclein. J Neurosci 2000; 20(16): 6021-9.

111. Magen I, Fleming SM, Zhu C, Garcia EC, Cardiff KM, Dinh $D$, et al. Cognitive deficits in a mouse model of pre-manifest Parkinson's disease. The European journal of neuroscience 2012; 35(6): 870-82.

112. Takakusaki K. Functional Neuroanatomy for Posture and Gait Control. J Mov Disord 2017; 10(1): 1-17.

113. Bostan AC, Dum RP, Strick PL. Functional Anatomy of Basal Ganglia Circuits with the Cerebral Cortex and the Cerebellum. Prog Neurol Surg 2018; 33: 50-61.

114. Lanciego JL, Luquin N, Obeso JA. Functional neuroanatomy of the basal ganglia. Cold Spring Harbor perspectives in medicine 2012; 2(12): a009621.

115. Kamata M, Higuchi H, Yoshimoto M, Yoshida K, Shimizu T. Effect of single intracerebroventricular injection of alpha-interferon on monoamine concentrations in the rat brain. Eur Neuropsychopharmacol 2000; 10(2): 129-32.

116. Konig A, Vicente Miranda H, Outeiro TF. AlphaSynuclein Glycation and the Action of Anti-Diabetic 
Agents in Parkinson's Disease. J Parkinsons Dis 2018; 8(1): 33-43.

117. Irshad Z, Xue M, Ashour A, Larkin JR, Thornalley PJ, Rabbani N. Activation of the unfolded protein response in high glucose treated endothelial cells is mediated by methylglyoxal. Sci Rep 2019; 9(1): 7889.

118. Belanger M, Yang J, Petit JM, Laroche T, Magistretti PJ, Allaman I. Role of the glyoxalase system in astrocytemediated neuroprotection. J Neurosci 2011; 31(50): 18338-52.

119. Allaman I, Belanger M, Magistretti PJ. Methylglyoxal, the dark side of glycolysis. Frontiers in neuroscience 2015; 9: 23.

120. Pun PB, Murphy MP. Pathological significance of mitochondrial glycation. Int J Cell Biol 2012; 2012: 843505.

121. de Arriba SG, Stuchbury G, Yarin J, Burnell J, Loske C, Munch $G$. Methylglyoxal impairs glucose metabolism and leads to energy depletion in neuronal cells-protection by carbonyl scavengers. Neurobiol Aging 2007; 28(7): 1044-50.

122. Shangari N, O'Brien PJ. The cytotoxic mechanism of glyoxal involves oxidative stress. Biochem Pharmacol 2004; 68(7): 1433-42.

123. Bose A, Beal MF. Mitochondrial dysfunction in Parkinson's disease. Journal of neurochemistry 2016; 139 Suppl 1: 216-31.

124. Nguyen M, Wong YC, Ysselstein D, Severino A, Krainc D. Synaptic, Mitochondrial, and Lysosomal Dysfunction in Parkinson's Disease. Trends Neurosci 2019; 42(2): 140-9.

125. Pajarillo E, Rizor A, Lee J, Aschner M, Lee E. The role of astrocytic glutamate transporters GLT-1 and GLAST in neurological disorders: Potential targets for neurotherapeutics. Neuropharmacology 2019; 161: 107559.

126. O'Donovan SM, Sullivan CR, McCullumsmith RE. The role of glutamate transporters in the pathophysiology of neuropsychiatric disorders. NPJ Schizophr 2017; 3(1): 32 .

127. Lai TW, Shyu WC, Wang YT. Stroke intervention pathways: NMDA receptors and beyond. Trends Mol Med 2011; 17(5): 266-75.

128. Parsons MP, Raymond LA. Extrasynaptic NMDA receptor involvement in central nervous system disorders. Neuron 2014; 82(2): 279-93.

129. Diogenes MJ, Dias RB, Rombo DM, Vicente Miranda H, Maiolino F, Guerreiro P, et al. Extracellular alphasynuclein oligomers modulate synaptic transmission and impair LTP via NMDA-receptor activation. J Neurosci 2012; 32(34): 11750-62.
130. Wang XS, Zhang ZR, Zhang XR, Chen SY, Shao B, Xie CL. Modulation of CaMKIla-GluN2B interaction in levodopa-induced dyskinesia in 6-OHDA-lesioned Parkinson's rats. Biomed Pharmacother 2018; 107: 769-76.

131. Trudler D, Sanz-Blasco S, Eisele YS, Ghatak S, Bodhinathan K, Akhtar MW, et al. alpha-Synuclein Oligomers Induce Glutamate Release from Astrocytes and Excessive Extrasynaptic NMDAR Activity in Neurons, Thus Contributing to Synapse Loss. J Neurosci 2021; 41(10): 2264-73.

132. Iovino L, Tremblay ME, Civiero L. Glutamate-induced excitotoxicity in Parkinson's disease: The role of glial cells. J Pharmacol Sci 2020; 144(3): 151-64.

133. Gröger A, Kolb R, Schäfer R, Klose U. Dopamine reduction in the substantia nigra of Parkinson's disease patients confirmed by in vivo magnetic resonance spectroscopic imaging. PLoS One 2014; 9(1): e84081.

134. Weingarten CP, Sundman MH, Hickey P, Chen NK. Neuroimaging of Parkinson's disease: Expanding views. Neuroscience and biobehavioral reviews 2015; 59: $16-52$

135. O'Gorman Tuura RL, Baumann CR, Baumann-Vogel H. Beyond Dopamine: GABA, Glutamate, and the Axial Symptoms of Parkinson Disease. Front Neurol 2018; 9: 806.

136. Figura M, Kuśmierska K, Bucior E, Szlufik S, Koziorowski D, Jamrozik Z, et al. Serum amino acid profile in patients with Parkinson's disease. PLoS One 2018; 13(1): e0191670.

137. Iwasaki Y, Ikeda K, Shiojima T, Kinoshita M. Increased plasma concentrations of aspartate, glutamate and glycine in Parkinson's disease. Neuroscience letters 1992; 145(2): 175-7.

138. Carrillo-Mora P, Silva-Adaya D, Villaseñor-Aguayo K. Glutamate in Parkinson's disease: Role of antiglutamatergic drugs. Basal Ganglia 2013; 3: 14757.

139. Cenci MA. Glutamatergic pathways as a target for the treatment of dyskinesias in Parkinson's disease. Biochem Soc Trans 2014; 42(2): 600-4.

140. Chase TN, Oh JD, Konitsiotis S. Antiparkinsonian and antidyskinetic activity of drugs targeting central glutamatergic mechanisms. J Neurol 2000; 247 Suppl 2: li36-42.

141. Nandhu MS, Paul J, Kuruvila KP, Abraham PM, Antony $S$, Paulose CS. Glutamate and NMDA receptors activation leads to cerebellar dysfunction and impaired motor coordination in unilateral 6hydroxydopamine lesioned Parkinson's rat: functional 

made available under aCC-BY-NC-ND 4.0 International license.

recovery with bone marrow cells, serotonin and GABA. Mol Cell Biochem 2011; 353(1-2): 47-57.

142. Kucheryanu VG, Kryzhanovskii GN. Effect of glutamate and antagonists of $\mathrm{N}$-methyl-D-aspartate receptors on experimental parkinsonian syndrome in rats. Bull Exp Biol Med 2000; 130(7): 629-32.

143. Qu X, Xu C, Wang H, Xu J, Liu W, Wang Y, et al. Hippocampal glutamate level and glutamate aspartate transporter (GLAST) are up-regulated in senior rat associated with isoflurane-induced spatial learning/memory impairment. Neurochem Res 2013; 38(1): 59-73.

144. Pita-Almenar JD, Zou S, Colbert CM, Eskin A. Relationship between increase in astrocytic GLT-1 glutamate transport and late-LTP. Learn Mem 2012; 19(12): 615-26.

145. McCarthy DJ, Alexander R, Smith MA, Pathak S, Kanes $\mathrm{S}$, Lee $\mathrm{CM}$, et al. Glutamate-based depression GBD. Med Hypotheses 2012; 78(5): 675-81. 


\section{Figure 2}

A

C

E

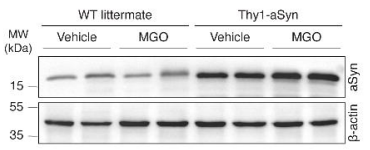

G

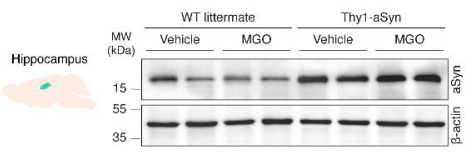

I

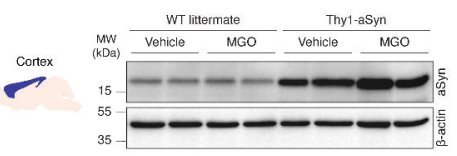

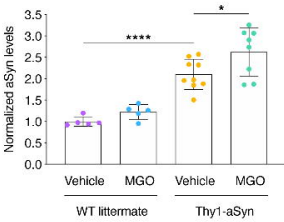
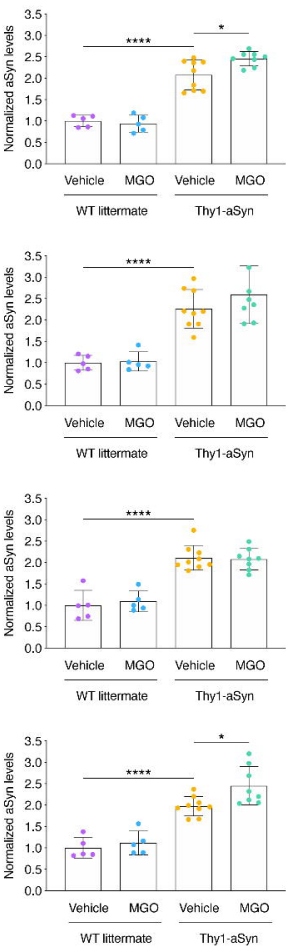

B

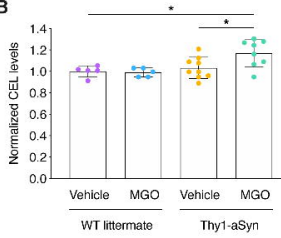

D

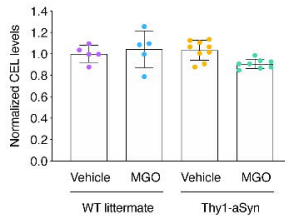

F

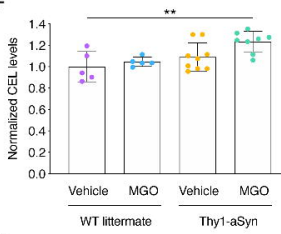

H

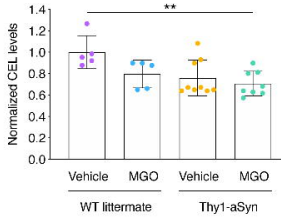

J

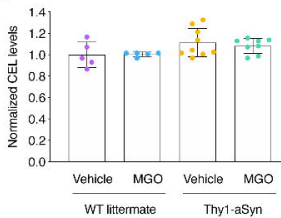


A
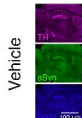

$\frac{0}{2}$

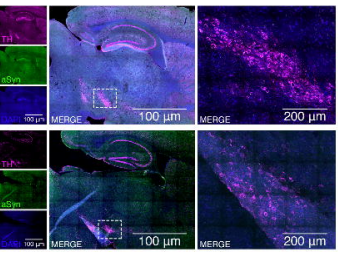

C

WT

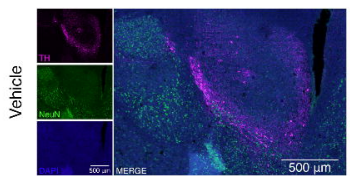

$\frac{0}{2}$

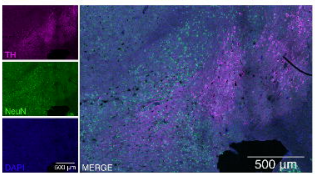

Thy1-aSyn

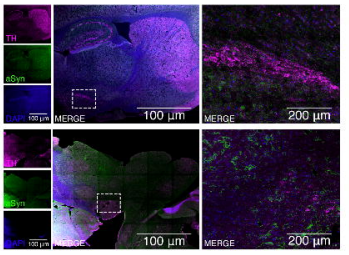

Thy1-aSyn
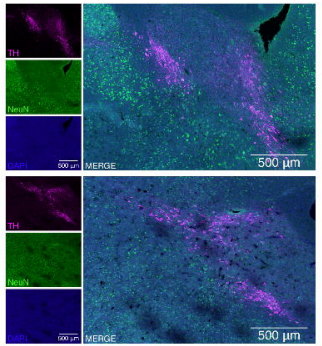

D
B

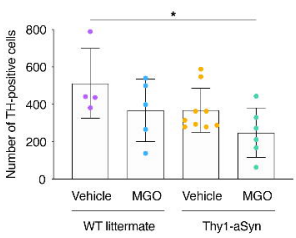

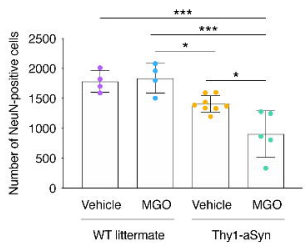

Figure 3

Thy1-asym 


\section{Figure 4}

A

Thy1-aSyn + MGO

vs

Thy1-aSyn + Veh

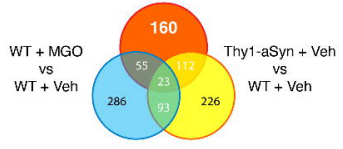

\section{C}

Biological Process

Pyruvate metabolic process (GO:0006090)

Regulation of dendritic spine development (GO:0060998)

Phosphate-containing compound metab. proc. (GO:0006796) 1

Peptidyl-threonine phosphorylation (GO.0018107)

Positive reg. of protein localization to P.M. (GO:1903078)

Neuron projection development (GO:0031175)

Excitatory postsynaptic potential (GO:0060079)

Molecular Function

Glutamate receptor binding (GO 0035254)

Calmodulin-dep. protein kinase activity (GO:0004683)

Ionotropic glutamate receptor activity (GO:0004970)

Oxidoreductase activity (GO:C016616)

Nucleotice kinase activity (GO.0019201)

Protein phosphatase 2B binding (GO:0030346)

Cadherin binding (GO:0045296)

Cellular Component

Mitochondrion (GO:0005739)

Ionotropic glutamate receptor complex (GO:0008328)

Fcoln-1-rich granule (GO:0101002)

Focal adhesion (GO:0005925)

Fcolin-1-rich granule lumen (GO:1904813)

Cytoskeleton (GO:0005856)

Actin cytoskeleton (GO:0015629)

KEGG Pathway

Glutamatergic synapse

Amphetamine addiction

Long-term potentiation

CAMP signalling pathway

Circadian entrainment

Dopaminergic synapse

Nicotine addiction

\begin{tabular}{|c|c|c|c|c|c|}
\hline \multicolumn{6}{|c|}{ Nicotine addiction } \\
\hline & 1 & $T$ & 1 & 1 & \\
\hline 0 & 2 & 4 & 6 & 8 & 10 \\
\hline
\end{tabular}

B

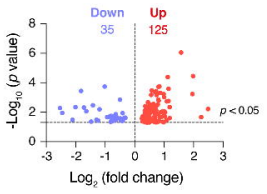

E

Down Up

\begin{tabular}{|l}
5 \\
4 \\
7 \\
7 \\
5 \\
4 \\
4 \\
5 \\
5
\end{tabular}

4

4

3

3

2

2

9

\begin{tabular}{l|l}
5 & 19 \\
0 & 5 \\
1 & 8 \\
4 & 8 \\
1 & 6 \\
4 & 10 \\
1 & 9
\end{tabular}

\begin{tabular}{l|l}
1 & 10 \\
0 & 9 \\
1 & 7 \\
2 & 9 \\
1 & 7 \\
0 & 8 \\
0 & 5
\end{tabular}
D

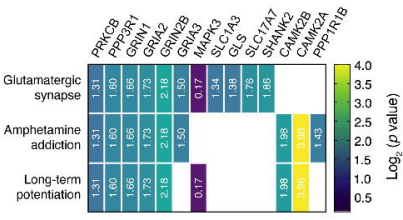

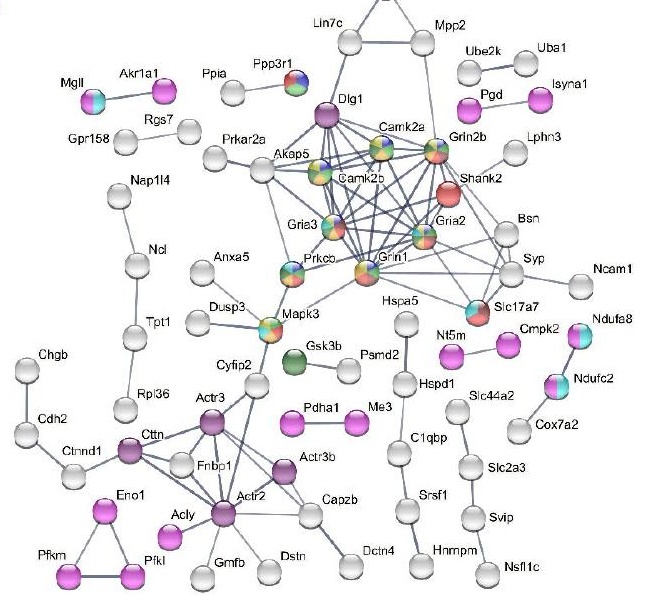

Glutamatergic synapse $\bigcirc$ Amphetamine addiction $\bigcirc$ Long-term potentiation

Circadian entrainment $\bigcirc$ Metabolic pathway $\bigcirc$ cAlMP signaling pathway $\bigcirc$ Dopaminergic synapse Retrograde endocannabinoid signaling Nicotine adciction $\bigcirc$ Tight junction 
A

$$
\begin{gathered}
\text { Thy1-asyn + MGo } \\
\text { vs }
\end{gathered}
$$

Thy1-aSyn + Veh

$W T+$ MGO
vs
$W T+V \in h$

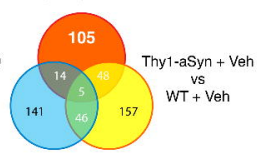

B

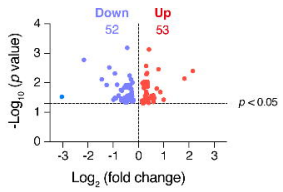

D

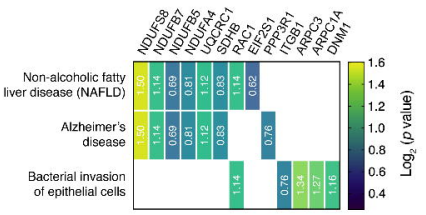

C

Biological Process

Respiratory electron transport chain (GO:0022904)

Translation (G0.0006412)

Ephrin receptor signalling pathway (GO:0048013)

Fc-y receptor signall pathway - phagocytosis (GO:0038096)

Fc-y receptor signalling pathway ( $G 0: 0038094)$

Fc receptor mediated stimulatory signal, path. (GO:0002431)

Mitoch. ATP synth. coupled electr. transp. (GO.0042775)

Molecular Function

Actin filament binding (GO:0051015)

NADH dehydrogenase - quinone (GO:0050136)

NADH dehydrogenase - ubiquinone (GO:0008137)

Purine ribonucleoside triphosphate binding (GO.0035639)

Cadherin binding (GO:0045296)

Actin binding (GO:0003779)

GTP binding \{G0:0005525\}

Cellular Component

Focal adhesion (GO:0005925)

Actin cytoskeleton (GO:0015629)

Mitochondrion (GO:0005739)

Secretory granule lumen (GO-0034774)

Ficolin-1-rich granule lumen (GO:1904813)

Ficolin-1-rich granule (GO:0101002)

Cytoplasmic vesicle lumen (GO:0060205)

KEGG Pathway

Non-alcoholic fatty liver disease (NAFLD)

Alzheimer's disease

Bacterial invasion of epithelial cells

Huntington's disease

Oxidative phosphorylation

Fc gamma R-mediated phagocytosis

Parkinson's disease

(

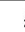

24

- $\log 10$ (Fisher' exact test $\mathrm{p}$ value)
E

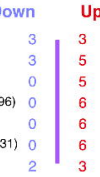

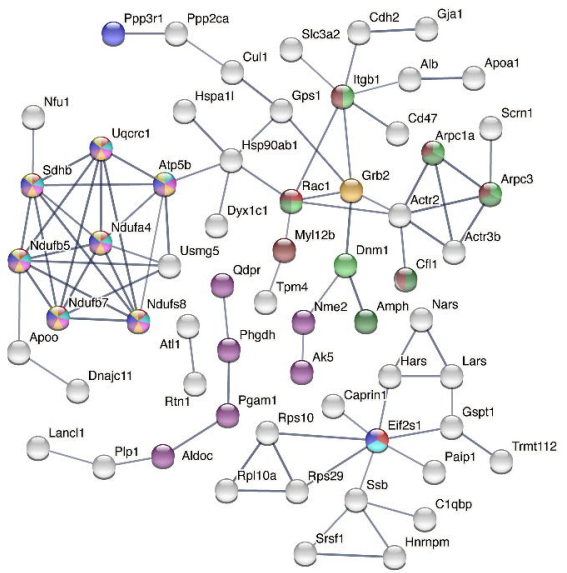

NAFLD Alzheimer's disease Bacterial invasion of epithelial cells $\bigcirc$ Huntington's disease Oxidative phosphorylation Fcy R-mediated phagocytosis Parkinson's disease

Thermogenesis

Metabolic pathways 


\section{Figure 6}

A aSyn

Glutamatergic

Neuron

Dopaminergic

Neuron

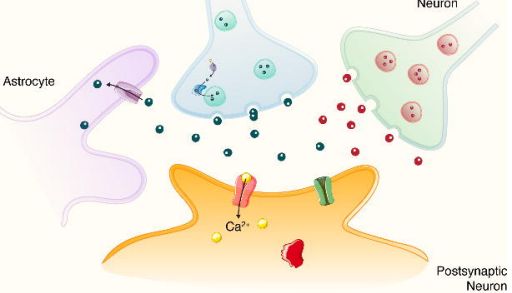

B aSyn + MGO

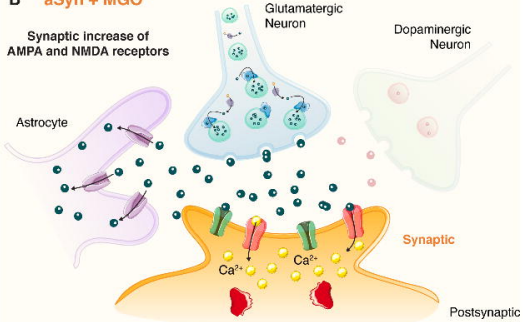

Neuron

\section{C $\quad$ aSyn + MGO}

$\begin{array}{lll}\text { Extrasynaptic increase of } & \text { Neuron } & \text { Dopaminergic } \\ \text { AMPA and NMDA receptors } & \text { Neuron }\end{array}$
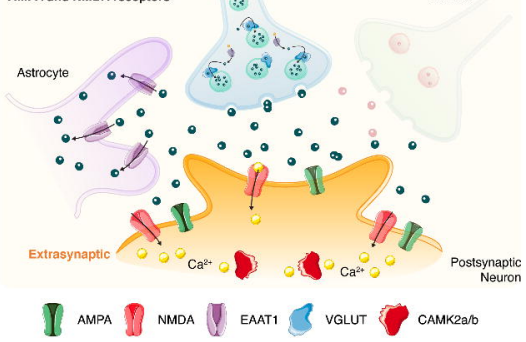

Glutaminase $\bigcirc$ Calcium $\odot$ Glutamate 98 Glutamine of Dopamine 


\section{Figure S1}

A

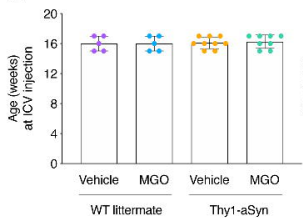

D

F
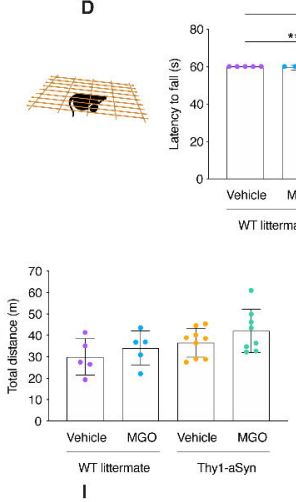

G

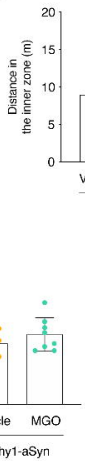

K
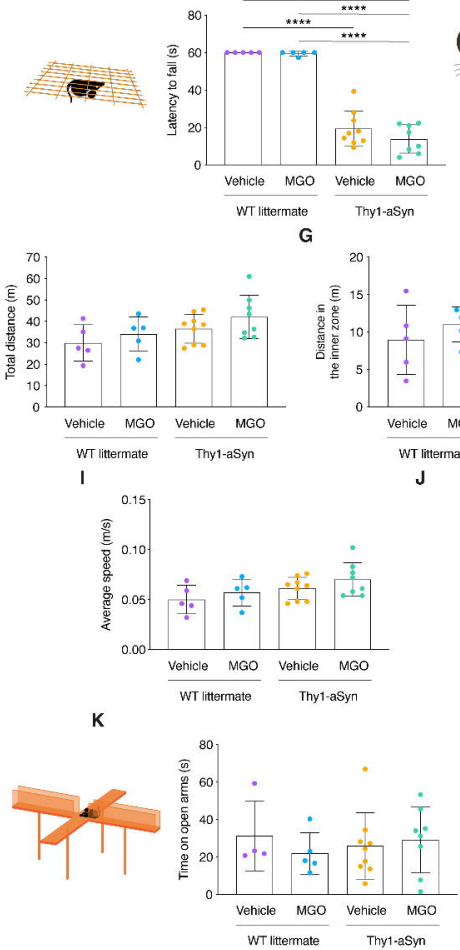

J$$
\text { J }
$$

c

0

16

19

20

21 weeks
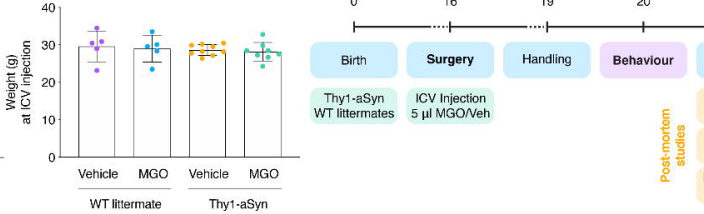

Histological

WT littermates $5 \mu \mathrm{l}$ MGONeh

E

Venicle MGO

H
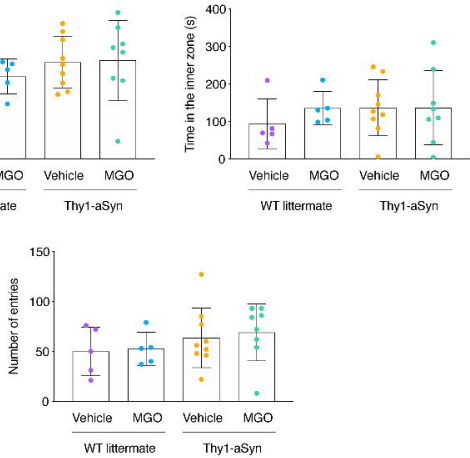

L

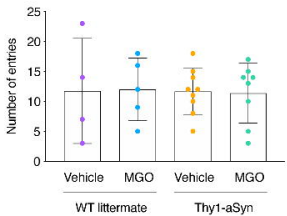

anatys

analysis analysis
Biochemical

$$
\begin{gathered}
\text { Vehicle MGO Vehicle MGO } \\
\text { WT littermate }
\end{gathered}
$$




\section{Figure $\mathrm{S} 2$}

A

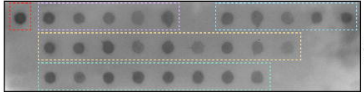

돓

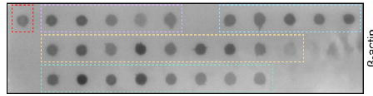

WT Vehicle

Midbrain

2

B

Striatum
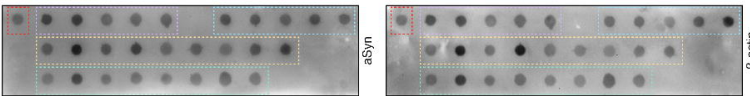

WT Vehicle

WT MGO

Thy-1-aSyn Vehicle

Thy-1-aSyn MGO

Pool

C

Cerebellum
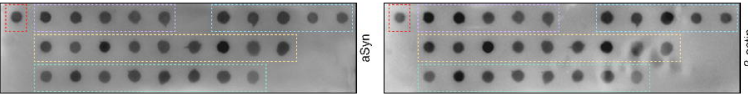

WT Vehicle

WT MGO

동 Thy-1-aSyn Vehicle

Thy-1-aSyn MGO

Pool

D

Hippocampus
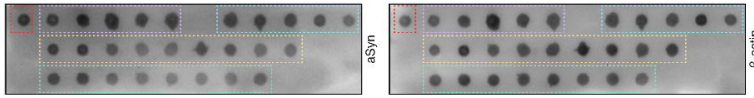

WT Vehicle

WT MGO

Thy-1-aSyn Vehicle

Thy-1-aSyn MGO

Pool

E

Cortex
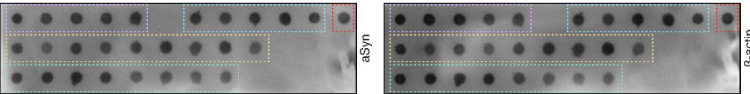

WT Vehicle

WT MGO

Thy-1-aSyn Vehicle

2 Thy-1-aSyn MGO

Pool 


\section{Figure S3}

A

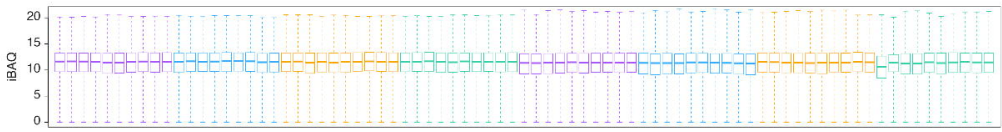

B

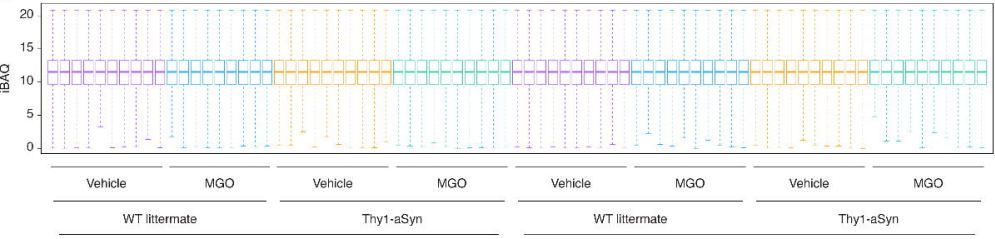

Cortex

Midbrain

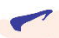



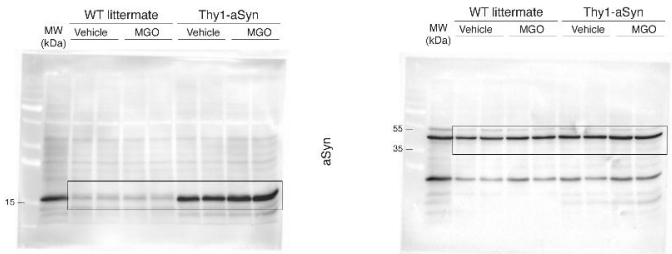

喜

B

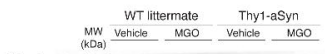

Membrane cutted

突

prior blotting

$$
15-
$$

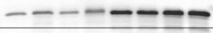

c

D

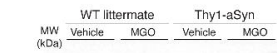

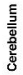

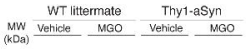

Membrane cutted

prior blotting

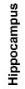

E

MW $\frac{\text { WT littermate }}{\text { Vehicle MGO }} \frac{\text { Thy1-aSyn }}{\text { Vehicle MGO }}$

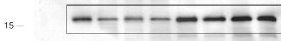

壱

\section{5}

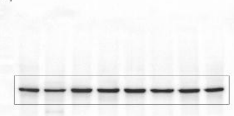

WT littermate Thy1-asyn

$\underset{\text { MWDa) Vehicle MGO Vehicle MGO }}{\mathrm{M}}$

WT littermate Thy1-aSyn

$\underset{\text { MW }}{\text { MDa }}$ Vehicle MGO Vehicle

放

돔

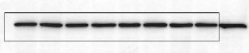

$55-$

WT littermate
MWDa)
(kehicle MG1-aSyn
Vehicle MGO

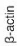

Membrane cutted prior blotting

点

Membrane cutted prior blotting

誉

$\underset{\substack{\text { MW } \\ \text { (KDa) }}}{\frac{\text { WT littermate }}{\text { Venicle MGO }}} \frac{\frac{\text { Thy1-aSyn }}{\text { vehicle MGO }}}{\text { MG }}$

55

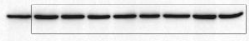

